\title{
Demand Side Management Opportunities, Framework, and Implications for Sustainable Development in Resource-Rich Countries: Case Study Qatar
}

\author{
Ebubekir S. Sahin ${ }^{a}$, I. Safak Bayram b, ${ }^{*}$, Muammer Koc ${ }^{d}$ \\ ${ }^{a}$ Economics, Graduate School Humanities And Social Sciences, Ibn Haldun University, Basaksehir, \\ Istanbul, Turkey \\ ${ }^{\mathrm{b}}$ Qatar Environment and Energy Research Institute, Hamad bin Khalifa University, Education City, \\ Doha, Qatar \\ ${ }^{c}$ Department of Electronic and Electrical Engineering, University of Strathclyde, Glasgow, UK \\ ${ }^{\mathrm{d}}$ Division of Sustainable Development, College of Science and Engineering, Hamad bin Khalifa \\ University, Education City, Doha, Qatar
}

\begin{abstract}
Over the last decades, global consumption of energy and environmental resources have been rapidly increasing due to advances in the production and transportation of goods, as well as reduced barriers to global trade markets. This trend raised sustainable consumption issues because of inefficient and wasteful use of resources, especially in resource-rich countries with high purchasing power and subsidized tariffs offered to residents. It is also well-known that resources abundance tends to lower financial development and limit productivity growth and social development. On the other hand, there is a growing acceptance that supply-side policies need to be complemented by demand-side management to support sustainable cleaner production and remedy aforementioned adverse impacts. In this study, we present the results of an investigation on demand-side management (DSM) opportunities and a framework developed for Qatar as a representative of an emerging resource-rich countries and discuss implications for cleaner production. The rationale behind is that Qatar is a commodity-dependent developing country, who, during the last five years, has experienced a population growth of $35 \%$, and an increase in electricity and water demand of $46 \%$ and 35\%, respectively. Similarly, during the same period, the national vehicle fleet has grown by more than twofold. These figures have ranked Qatar at the top of the per-capita energy, carbon, and water consumption list in the world and increased environmental vulnerability and reduced climate resilience. To that end, the objectives of this study are to: (1) construct a DSM framework tailored to the needs of resource-rich country like Qatar from economic, social, environmental, and technical aspects; (2) present, analyze, and discuss
\end{abstract}


the results of a survey that reveals the perceptions, attitudes, and responses of local residents towards the applicability of DSM policies; and (3) discuss methods and solutions to achieve cleaner energy consumption. The conducted survey covered electricity, water, and transportation sectors and showed that residents have low awareness about their consumption habits, but they have high willingness to reduce their consumption levels. In the last section, we present the survey results and discussions as a reference for policy-makers to promote the most promising DSM options in Qatar. To the best of authors' knowledge, this is the first survey-based study conducted in the Gulf Cooperation Council region where a significant portion of world's oil and natural gas resources are extracted. Therefore, the results could provide insights to other resource-rich countries with similar characteristics to devise more efficient policies for promoting welfare-enhancing and sustainable consumption behavior.

Keywords: Demand Side Management Framework, Resource-Rich Countries, Sustainable Consumption Behaviors, Survey, Cleaner Production

${ }^{*}$ Corresponding Author: I. Safak Bayram (e-mail: safak.bayram@strath.ac.uk), Qatar Environment and Energy Research Institute, Doha, Qatar and Department of Electronic and Electrical Engineering, the University of Strathclyde, Glasgow, UK 


\section{Introduction}

Developing resource-rich countries, such as the ones in the Gulf Cooperation Council (GCC), have been taking bold steps towards acquiring policies and practices to promote sustainable development by harmonizing economic growth, environmental protection, and social inclusion (Hertog and Luciani, 2009). Successful implementation of sustainability actions relies on mobilization of all stakeholder around the new agenda. All GCC members, namely, Qatar, Bahrain, Saudi Arabia, Kuwait, United Arab Emirates (UAE), and Oman have joined United Nation's (UN) high-level political forum on sustainable development assess the progress made according to UN's 2030 agenda for sustainable development (United Nations Sustainable Development, 2019). Although these states own significant oil and natural gas reserves and enjoyed economic boom for several decades now, they are experiencing vital issues related to economic diversification, wastage of resources, air-quality and health related issues (Friedrichs and Inderwildi, 2013). Another rising problem is the rapidly growing domestic demand for cheap energy and water resources due to high subsidies offered to residents. High consumption of such resources, which is more than most industrialized countries, is now critical factor for energy and environmental energy, and the region will be vulnerable to economic shocks if appropriate sustainability measures are not taken (Salahuddin and Gow, 2014). Current modes of consumption and production lead to unsustainable outcomes and recent research schemes focus on the sustainability of energy systems by concentrating on technological, economic, and social aspects (Sáez-Martínez et al., 2016). Demandside management (DSM) is vital for achieving sustainability goals as DSM aims to prevent resource production waste (e.g., electricity, water, etc.) and increase more efficient use of valuable resources.

DSM is further linked to policies that promote environmental awareness and cleaner energy production. Most electric utility companies are required to address a new societal and regulatory obligation- lowering green-house gases- to tackle climate change. In electricity generation, green-house emissions are time-dependent and actual emissions are based on the real-time generation mix (e.g., coal, hydro, diesel, etc.) (Baumgärtner et al., 2019). In peak system hours, utilities typically employ fastresponse diesel generators to match system demand. DSM applications can eliminate the use of such 
pollutant generators by reducing consumption levels. For instance, current DSM measures in the United Kingdom can reduce $\mathrm{CO}_{2}$ emission nearly by $2 \%$ per consumer (Lau et al., 2015). DSM's positive impacts on environment would typically be higher in regions with untapped demand-reduction potential. Resource-rich countries exhibit such behaviour as energy prices are typically subsidied and high household-income limits resource preservation.

The history of sustainable development concept goes back to the industrial revolution when the world has experienced a significant population growth due to improved standards of living (Galor and Moav, 2005; Max Roser, 2016; OECD, 2015; WHO, 2016). As a result, consumption levels in almost every region and of every sort have naturally increased. This trend is further supported by the significant paradigm shift from supply is to meet the demand to demand is artificially created by the supply (JeanBaptiste Say, 1836; The Economist, 2017) which triggered an excessive and artificial consumption growth. As a result, a variety of environmental, social, and economic problems such as climate change (US Department of Commerce, NOAA, 2017), energy resource depletion (Benes et al., 2015), environmental pollution, and social inequity has evolved and raised concerns about sustainability .

Among all human needs, energy resources and water come to the fore due to their vital roles in in our daily lives and the high risk of depletion. In the last 45 years, the increase in total energy consumption in all sectors is $139 \%$ (from 5,661 mtoe to 13,511 mtoe) (British Petroleum, 2018) while the growth in world's population is only $92 \%$ (from $3.9 \mathrm{~b}$ to $7.5 \mathrm{~b}$ ) (World Bank, 2018a). This singularity demonstrates that the consumption rate has outpaced the population growth because of consumption hike in resource-rich and developed countries (Figure 1). Continuous improvements in supply-side technologies such as higher efficiency appliances, vehicles, and processes have created a vicious cycle between consumption and production. To have sound and long-term solutions to address consumptionrelated issues, demand-side activities that aim to shape consumer needs, should be prioritized especially for resource-rich countries who experience resource curse that cause adverse social, economic, and environmental impacts (Friedrichs and Inderwildi, 2013).

Demand-side management (DSM) is the planning applications of programs designed to shape resource (e.g., electricity, water, transport) use in ways that will produce desired changes aggregated load profiles (Potter et al., 2018). Moreover, DSM is a part of cleaner production concept that aims to 
prevent wastage of resource generation, while increasing efficiencies in various sectors including electricity, water, and transportation. Overall, DSM can be realized by three approaches, namely economic, technological, and social (Bayram and Ustun, 2017). The economic approach employs financial incentives or differential pricing to motivate consumers to shift and lower their consumption levels. The technological approach typically utilizes remote controlling devices such as smart thermosthats, sensors, load switches. This way demand management can be coordinated with signals sent from the utility company in an automated fashion. Social approach aims to increase awareness among end-users to change consumption behaviours and reduce wastage (Dulleck and Kaufmann, 2000; Eto, 1996; Hirst et al., 1992; The Brattle Group, 2007). A detailed overview is presented in the next section. DSM applications are recognized (Hayes et al., 2013; Murthy Balijepalli et al., 2011) and employed in various critical sectors around the world and most common ones include electricity, water, and transportation (Alasseri et al., 2017; Andersen et al., 2006; Eissa, 2011; Gils, 2014; Paulus and Borggrefe, 2011; Wang et al., 2010; Warren, 2014). To that end, this paper aims to formulate and construct a DSM framework for resource-rich countries through a case study for Qatar. The framework is constituted from four main pillars, namely social, economic, environmental, and technical, and contains a total of 18 different components. Next, we present the results of a conducted survey among the residents of Qatar to understand resource consumption patterns, and opportunities and barriers for DSM implementation.

It is important to note that traditionally electricity, water, and transportation sectors are independent of each other. Therefore, demand-side policies and frameworks for these sectors are designed separately. On the other hand, this paper targets these three sectors at the same time. The rationale is that in the Gulf Cooperation Council region, these sectors are strongly linked together due to the way they were designed. The electricity sector energizes air conditioning which is vital to a maintain comfortable lifestyle for almost ten months of the year. Moreover, due to the lack of natural water resources and aquifers, the main source of potable water is secured by desalted seawater (DW). DW represents nearly $99 \%$ of municipal tap water and generated through energy-hungry water treatment plants powered by electricity. In addition, due to extreme desert conditions, tap water is stored and chilled in central plants and pumped into residential units (Darwish et al., 2015). In some locations, 
houses contain rooftop water chillers in addition to water heaters. Last, transportation sector in Qatar is a major contributor to energy-related carbon emissions, and in line with the transition to a low-carbon economy, the State of Qatar has set a bold goal to replace 10\% of its vehicle fleet with electric vehicles by 2030 . Electric vehicles have proven their ability to reduce GHG, reduce our dependence on oil, and are uniquely able to participate in an interactive energy grid of the future by improving system flexibility. More specifically for Qatar, electric transportation means to replace gasoline with electricity that is generated from cleaner sources such as natural gas and solar energy. Electric vehicles emit less GHG and air pollutants over their life cycle than gasoline-powered vehicles. (Bayram, 2019a; "Green Car Initiative", 2017). These efforts are further supported by adoption of electric buses and deployment of public charging stations (“First electric car," 2018). Furthermore, Qatar Rail network, which is energized by electricity, has partially became operational and the project will be completed next year ("Qatar Rail to Open," 2019). To that end, we perform a holistic approach to examine the interplay between these three sectors and provide a reference framework for decision-makers. This intersecting nature is unique to Qatar and the GCC region because most resource-rich countries (e.g., USA, Canada, Norway) have a variety in their energy mix and own natural water resources (Friedrichs and Inderwildi, 2013). 


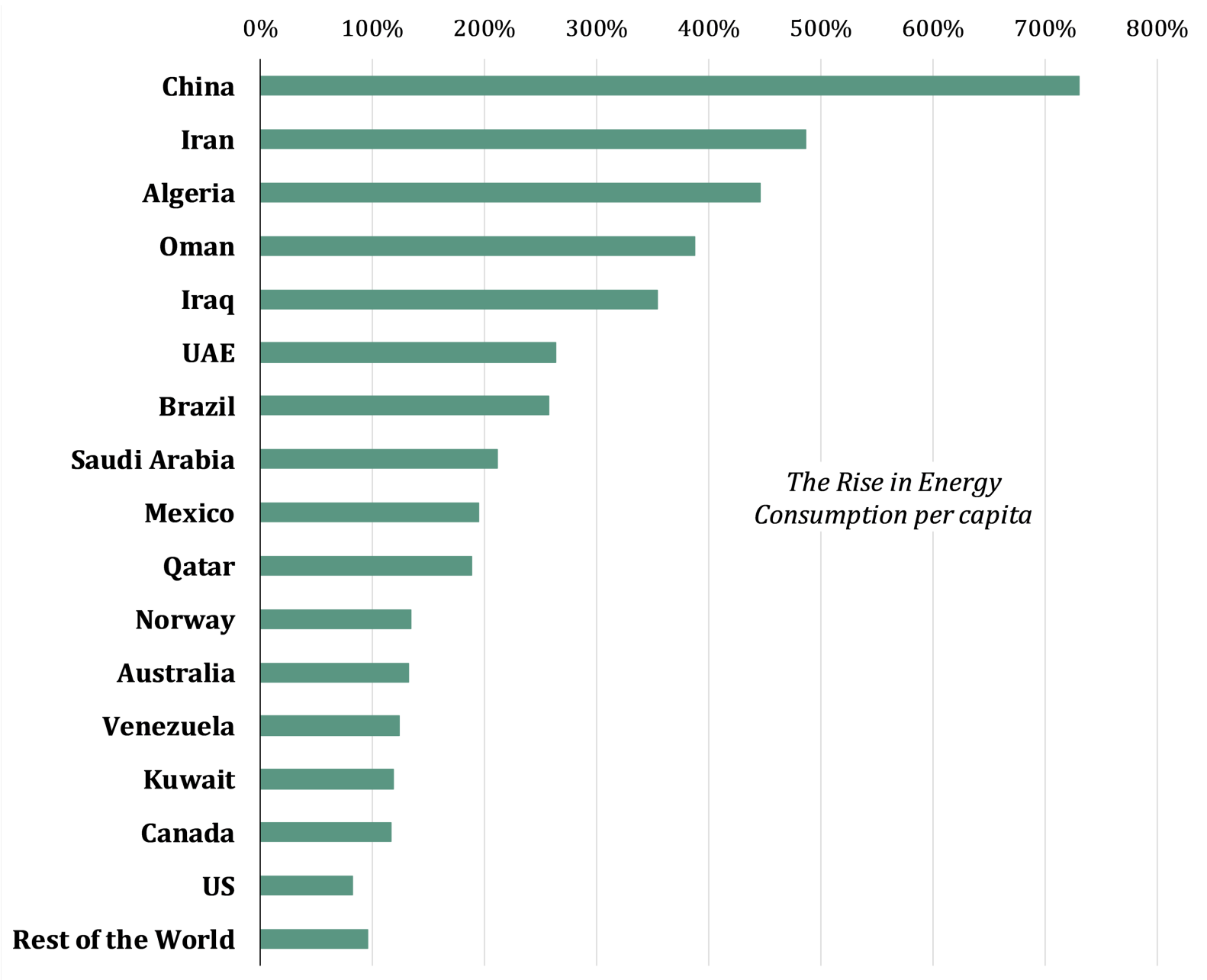

Figure 1. The rise in total energy consumption per capita of Resource-Rich Countries between 1973-2017.

The current literature includes a variety of demand-side management frameworks for a specific region or country as described in detail in the next section (see Table 1 for the summary and ref. (Meyabadi and Deihimi, 2017)). However, the content and the applicability of such programs depend very much on social, economic, and cultural local dynamics, and there is no off-the-shelf DSM program. The difference between not only resource-rich and resource-lack countries but also developed and developing countries with different circumstances become a subject of studies to have distinctive and tailored DSM programs (Khan, 2019; Nicholls and Strengers, 2015). Additional set of challenges also exists in resource-rich countries which is further classified as established and emerging economies (Friedrichs and Inderwildi, 2013; Nolan and O'Malley, 2015). The case for Qatar and the Gulf Cooperation Council (GCC) countries falls into the latter case and such countries face specific barriers 
to reduce resource consumption. Institutionalized energy subsidies are part of an unwritten and inefficient social welfare program which triggers high-carbon lifestyles, wastage, and reduces government revenues (El-Katiri and Fattouh, 2015). For instance, easy access to domestic fuel has a crowding out effect on energy mix and economic structures. In the entire GCC region, electricity is generated by domestic crude oil and natural gas, while solar generation is expected to flourish within the next five years. Another differentiating factor is that a significant portion of the population $(85 \%$ in Qatar) is composed of expatriates who, unlike many of developed countries, cannot enjoy the social benefits provided to locals due to lack of citizenships policies offered to foreigners. To capture the local dynamics, it is very critical to design DSM policies based empirical data, such as the one presented in this paper, to identify best DSM options.

Further details for the case study on Qatar can be explained as follows. After the discovery of oil in 1939 and natural gas in 1972, the economic landscape in Qatar has drastically shifted to the oil/gasbased development, which transformed the economy and the society with increasingly apparent impacts on the environment. The economy has grown with the help of oil and gas revenues while the population reached to 2.64 million in 2017 (World Bank, 2018b) from 0.1 million in 1970 (Metz, 1994). Along with the policies shaped by a national program called Qatar National Vision (QNV) 2030 (Qatar General Secretariat for Development Planning, 2008), introduced in 2008, Qatar has become the wealthiest country per capita (i.e., GDP per capita of \$128k in 2017 based on PPP-purchasing power parity) (World Bank, 2018c). As of 2017, Qatar has the third largest natural gas reserves in the world after Russia and Iran with a proven 25 trillion cubic meters (tcm) reserves accounting for $13 \%$ of the earth's total gas reserves ("Biggest Natural Gas Reserves," 2013). Around 79\% of total 164 billion cm gas production is exported, while the rest is used for domestic needs as of 2017 (OPEC, 2017). As of many other sectors like water supply through desalination in the country, Qatar's energy generation sector also depends on natural gas extraction; almost $100 \%$ of total electricity is produced by combusting fossil fuels (Central Intelligence Agency, 2012). Due to such characteristics of the country, increasing wealth, growing population and rich natural resources boost the consumption levels in the country in last decades. Over the past five years, the electricity demand has increased by 46\% from 30 TWh in 2011 to 44 TWh in 2017 and maximum demand has increased by 47\% from 5.3 GW in 2011 to $7.8 \mathrm{GW}$ in 2017, while water 
consumption (almost entirely depend on energy-intensive seawater desalination facilities) has reached $543 \mathrm{Mm} 3$ in 2017 from $401 \mathrm{Mm} 3$ in 2011 with a 35\% rise (Bayram, 2018; Kahramaa, 2016a; Ministry of Development Planning and Statistics, 2018). Besides, Qatar's vehicle fleet has grown at a rate of $115 \%$ from 525k to 1.3 million (CEIC Data, 2017). As a result of these consumption figures, Qatar has the highest $\mathrm{CO} 2$ emissions in the world totaling up to 45 metric tons/capita (Global Carbon Atlas, 2018) Furthermore, nearly $59 \%$ of the total electricity generation was used in residents and buildings mainly for space cooling, $29 \%$ was consumed in industry, $6 \%$ was used for auxiliary consumers, and $6 \%$ went to transmission losses (Kahramaa, 2016a). The vast majority of the domestic electricity consumption is due to the need for cooling, and cooling consumption easily exceeds half of the total consumption during summer months. Monthly cooling consumption estimates are presented in

Figure 2.

The main drivers of electricity consumption in Qatar can be classified into four groups: (1) Qatar is in the zone of arid desert climate. This characteristic necessitates residents to cool indoor air and water at all times for almost half of the year, and partially during the rest of the mild seasons. Hence, electricity consumption stays steady during the day; however, significant variations are seen between seasons unlike many studies focusing on the daily electricity usage profiles (Khan et al., 2019). Additionally, cooling accounts for about $60 \%$ of total residential electricity consumption (Kahramaa, 2015); (2) Highly subsidized tariffs are likely to be the primary reason behind over-consumption of resources. According to the International Monetary Fund (IMF) ("Energy Subsidies," 2015), in terms of energy subsidy per capita, Qatar ranks the first by far in the world with $\$ 6,000$ per capita as shown in Figure 3. Even though subsidies are meant to distribute wealth to society, they lead to overconsumption of resources through emissions and health hazards in the long run; (3) Unbalanced population growth, economic development, environmental preservation; and (4) Common social belief is that providing energy for the residents is one of the government's primary duties.

As DSM typically focuses on modifying consumption patterns of people individually and/or as a group, the success of DSM policies depends on various factors including the target population, demographic structure, local culture, and the targeted sector. Therefore, a comprehensive analysis of different aspects is required to decide which type of DSM application should be designed and in what 
ways it should be implemented to maximize the benefits. This study first explores the potential for applicability of DSM in Qatar for three sectors: transportation, water, and electricity; and considers four aspects, economic, social, environmental, and technical by taking into consideration the unique dynamics and circumstances of the country. To this end, this study is the first of its kind in Qatar filling a major gap and need to determine the ways and means of a successful DSM policy implementation in Qatar.

In the next section, we present a comparative literature review on DSM. In section 3, as a methodology, a tailored DSM framework is constructed and discussed. The survey set-up and concept are provided in section 4. In section 5, the results of the survey study revealing Qatar residents' perception and attitudes toward potential DSM policies are provided and discussed. In the sixth and last section, we present the conclusions and recommend potential future studies.

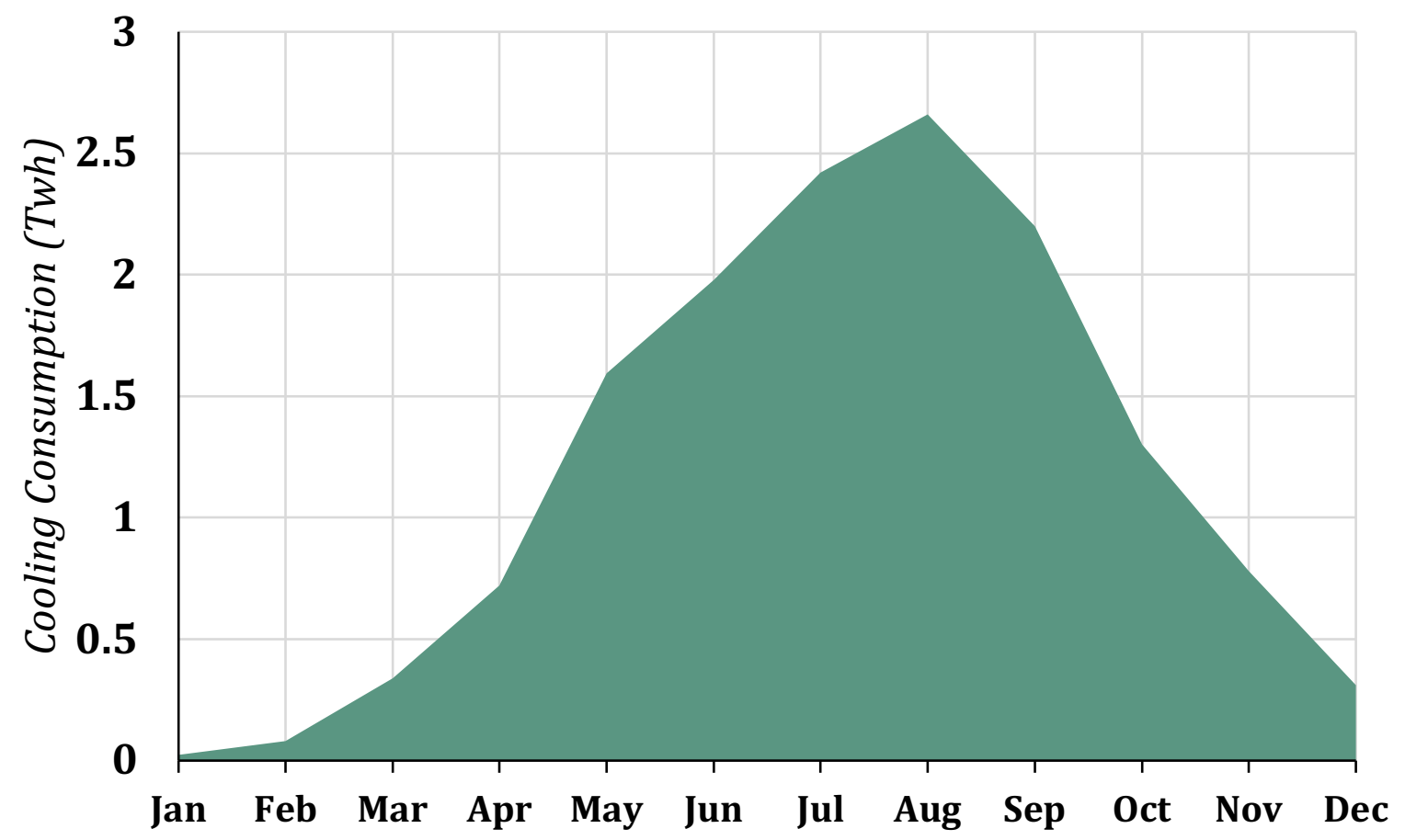

Figure 2. Monthly residential electricity demand for cooling in 2016 in Qatar (reproduced from (Saffouri, 2017)). 


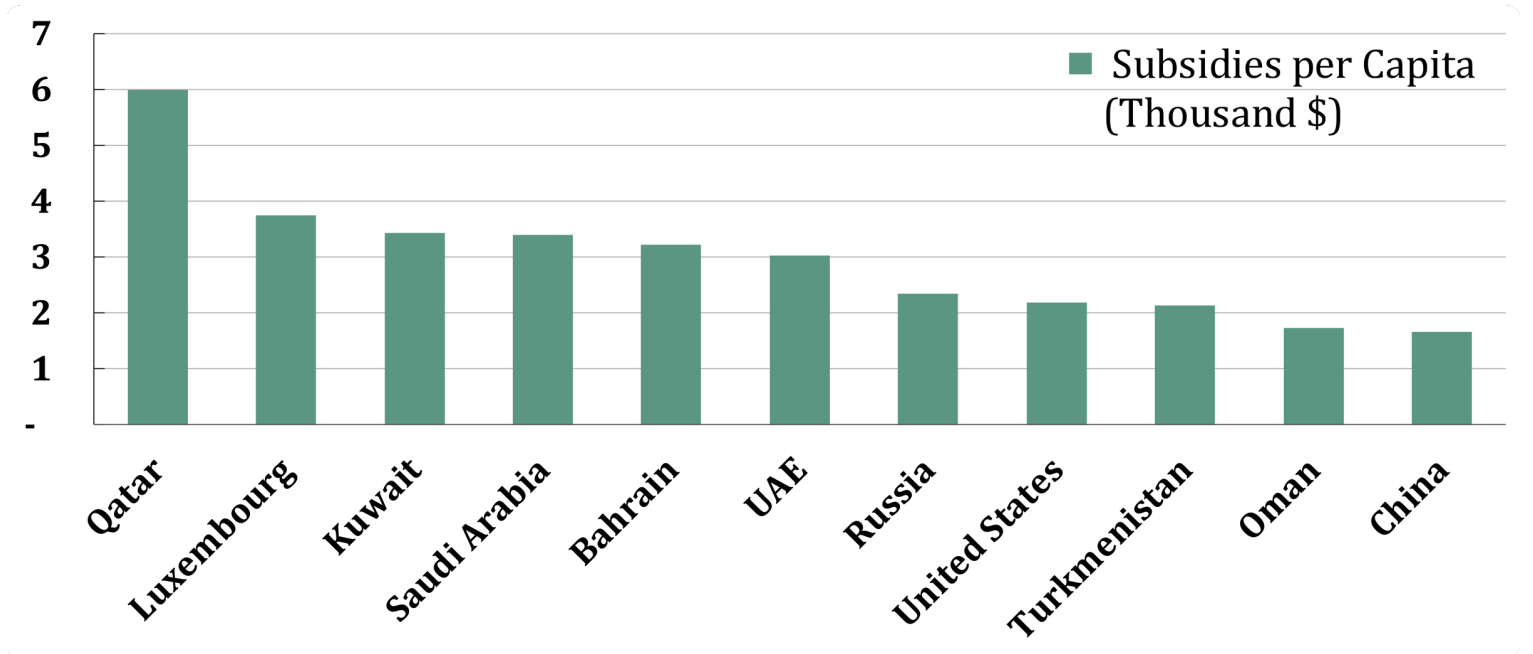

Figure 3. Total annual subsidy per capita figures by country in 2015 (“Energy Subsidies,” 2015).

\section{Literature Review}

DSM is crucial to achieve sustainable development goals, therefore, there has been a growing body of literature on sustainable DSM theories, framework, policies, and applications in various sectors all around the world. We classify the related literature as follows. First, we present a brief history of DSM and discuss various DSM techniques and sub-categories. Then, after we provide the objectives, benefits of and barriers for DSM, several known applications from electricity, transportation, and water sectors are presented. In the last part, we present a comparative overview of various DSM programs.

After the DSM term has been firstly coined in 1970s (global oil crises (Torriti, 2017)) by Clark W. Geelings from the electricity sector in the US (Gellings, 1981), it spreads over to other countries and sectors such as water (Butler and Memon, 2016), transportation (Dorsey, 2005), and food (Bajželj et al., 2014). DSM can be classified mainly into two categories: (1) energy efficiency (EE), which mostly focus on influencing people to use more efficient products, and (2) demand response (DR), which aims to modify people's consumption habits and behaviors to reduce their consumption (Albadi and ElSaadany, 2007). Nowadays, researchers aim to improve the impact of DR programs by developing novel techniques such as introducing a machine learning algortihm (R. Lu et al., 2018; Vázquez-Canteli and Nagy, 2019). One of the sub-category of DR, direct-load control, contains remote-controlling requiring no consumer interaction; therefore it should not be considered as a policy modifying human behaviors. 
Additionally, DR has two sub-categories: price-based programs (PBP) and incentive-based programs (IBP). IBP use incentives to alter end-user behavior patterns while PBP leans on the changes in prices in different time periods (off-peak, peak) (X. Lu et al., 2018). The required time periods to develop, apply and gain the ultimate reductions for any DSM application can be seen in Figure 4. Load Reduction Delivery (LRD) approach can bring the consumption reductions in a very short period of time with rapid response, but with minimal permanent behavioural changes to the end-users whereas social behavioral change programs (SBCP) may take decades to develop, implement and gain the benefits, but their impacts on permanent behavior change would be quite significant, multi-dimensional and comprehensive. Customer engagement in DSM policies is a world-wide issue as the endusers do not comprehend the way resources are used. The work presented in (Annala et al., 2018) shows that even in Finland, one of the forerunner countries in DSM and renewable energy layout, the main barriers to DSM utilization in electricity sector are related to customer engagement and automation of their demand response.

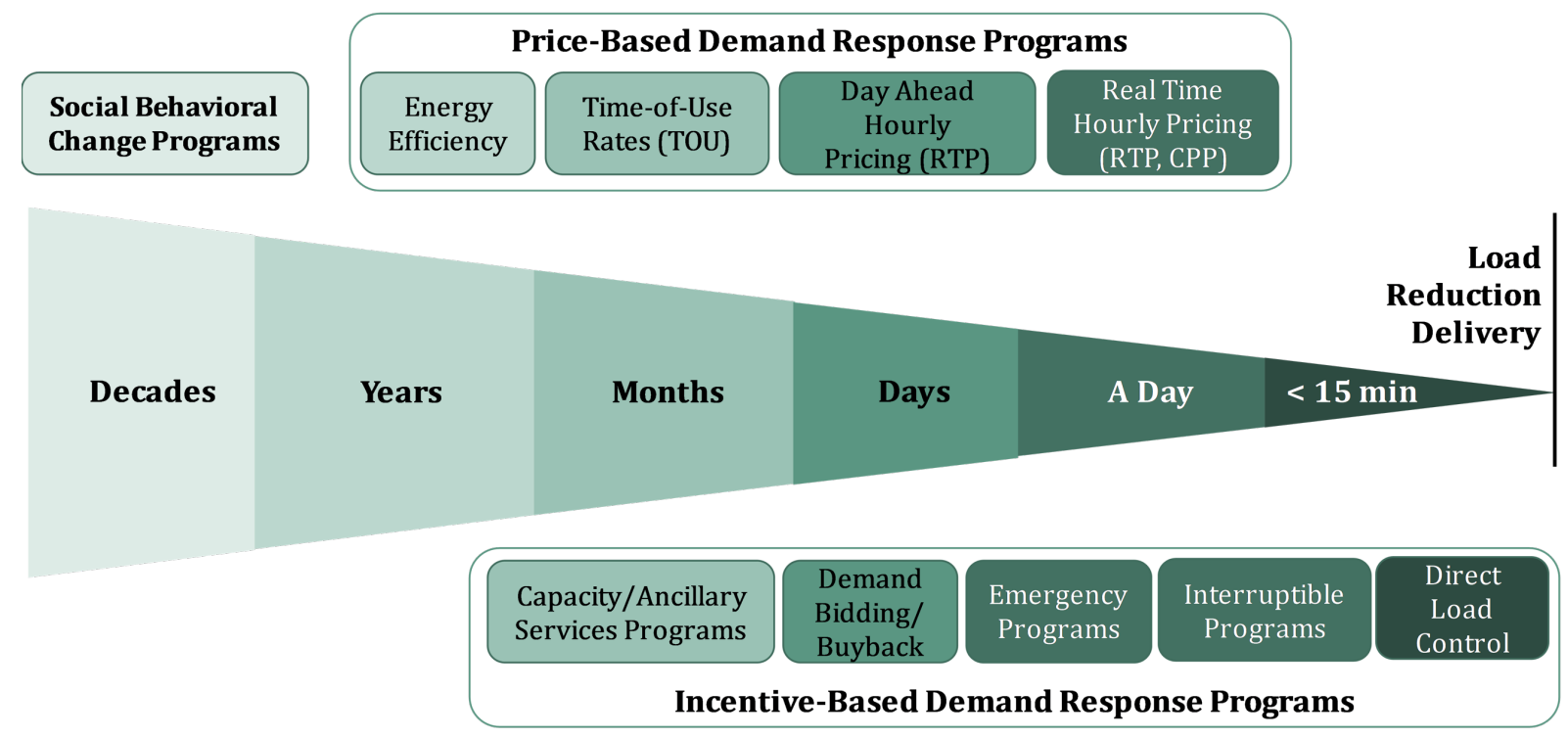

Figure 4. Different time needed to implement different DSM programs (reproduced from (U.S. Department of Energy, 2006)).

DSM typically targets to rationalize investments in energy supply infrastructure, balancing between supply and demand, increasing the systems' reliability and security, slowing down the depletion of natural resources and contributing on the reduction of $\mathrm{CO}_{2}$ emissions. It benefits different actors by various ways such as reducing the bill payment for end-user, developing a resilience point for the certain 
resources for the nations (IPART, 2001) and reducing expenses for the utility companies. In terms of barriers to DSM, six aspects have been specified before implementation; technical, structural, regularity, educational, economic and traditional (Cigre Working Group, 2011). Moreover, three barriers have been referred as after implementation; rebound effect, fluctuated energy prices and free riders (Braithwaite et al., 1994).

Apart from the electricity sector, DSM has been widely used in various other sectors. In the transportation sector, travel demand management (TDM) has been used to minimize the need for travel in order to reduce traffic jams, fossil fuel consumption and consequent air pollution and life quality issues. Some of the common methods under TDM can be summarized as follows (Cairns et al., 2008): workplace travel plan, school travel plans, tailored travel planning, public transportation information and marketing, travel awareness campaign, car club offers, car sharing/carpooling, teleworking working, teleconferencing, home shopping. In the water sector, water demand management (WDM) seeks to find a way to reduce overall water consumption by specific policies. Some of the well-known WDM policies are as follows: re-use of sewage effluents (Mara, 2013), water conservation and improved efficiency of water use, virtual water policy (Jiang et al., 2015), technical and technological improvements (Cominola et al., 2015).

Sustainable energy consumption is particularly important for the electricity sector in Qatar and similar resource-rich countries of the Middle East because electric utility business is a unique supplydemand system with the following characteristics. First, supply and demand must match in real-time, with tight control on the supply-side, and traditionally in supply following demand fashion. Second, there is very little room for energy storage due to high-cost, hence, there are no "backorders". Third, the underlying network is capital-intensive and requires significant debt financing. In addition, power systems are uniquely critical as they play a key enabling role across various critical infrastructures such as water desalination and distribution, communication, transportation, health care, and very few industries would survive without a secure and continuous supply of electricity (Pérez Arriaga and Knittel et al, 2016). The primary focus of the electricity sector in addressing climate change includes enhanced efficiency, improvement of green renewable energy sources, and utilization of low carbon fuels. It is noteworthy that such a transformation will be extensive, long-term, and touches every aspect of 
electricity grid from supply to end users. These changes require better deployment of information and incentives to bring cleaner production capabilities to utilities and customers.

In the literature, there are various studies exploring the possible impact of specific DSM applications. For the case of China, Mah et al. revealed the perception of people towards dynamic electricity pricing (Mah et al., 2018). In another study, Wang et al. calculated energy savings under possible price-based DSM scheme (Y. Wang et al., 2018). Wang et. al explores the impacts of real time pricing DSM program on residential electricity consumption (H. Wang et al., 2018). In the GCC region, Alasseri presented a study to find the most suitable DSM policy for the electricity sector in Kuwait (Alasseri et al., 2017). Moreover, Gaouda et al. discussed possible energy savings after DSM implementation in the United Arab Emirates (UAE) (Gaouda et al., 2013). For the case of Saudi Arabia, Eissa et. al. compared different DR programs and investiageted their environmental impacts (Eissa, 2011). Moreover, (Kiani, 2017) conducted a simulation study on air conditioner units in residential and commercial sectors to understand their impacts on the UAE economy and forecasted energy use for various scenarios. In the State of Qatar, specifically after the introduction of QNV 2030 program, there has been a growing amount of research on DSM and energy conservation in electricity, water and transport sectors. Jasim et al. conducted a study to discover the potential impact of treated waste water effluent policy (Jasim et al., 2016), while Jraiw investigates the impact of travel demand management policies on road safety (Jraiw, 2015). In electricity sector, Bayram et al. presented the role of DSM on PV renewable energy integration for Qatar in 2017 (Bayram and Koc, 2017) and, in 2018, they further revealed the electricity consumption patterns in Qatar (Bayram et al., 2018). On the other hand, to the best of our knowledge, the present study is the first comprehensive study on DSM frameworks covering various sectors and taking the unique characteristics, norms and culture into account. We believe that the study will form a solid basis for any DSM research in major sectors for resource-rich countries to construct on.

When it comes to the existing DSM applications in Qatar and other similar resource-rich countries, there are initiatives regarding DSM even if they are not compiled under the same heading as listed in Table 1. Tarsheed, for example, is a national sustainable energy program for conservation energy efficiency in Qatar. It has been introduced by Kahramaa, the local utility company, in 2012 to reduce 
the over-consumption electricity and water as they are tightly coupled ("Kahramaa announces," 2012). The reduction targets per capita were set as $35 \%$ and $25 \%$ for the water and electricity until 2022 (Kahramaa, 2012). According to the Kahramaa, the program has already achieved some critical milestones such as reducing electricity consumption per capita by $17 \%$ and water consumption per capita by $18 \%$ (Kahramaa, 2016b). Apart from Tarsheed, other initiatives introduced by Kahramaa can be considered as DSM policies or auxiliary for DSM policies. Starting from 2015, Kahramaa increased the water tariffs in order to nudge its customers to conserve water ("Kahramaa hikes tariffs," 2015). The effects of the price policy on water is currently a research topic in universities and research centers. Moreover, in January 2018, Kahramaa launched its new information sharing service, which sends an SMS notification to customer's phone to inform them about their monthly electricity and water consumption even if the customers are eligible to not to pay the bills due to the government incentives (“Kahramaa SMS service,” 2018). Before this information service, Kahramaa had also started to send SMS notifications to customers to educate them about the consumption patterns and encourage them to conserve more. Tarsheed has other sets of objectives and projects in order to achieve efficiency thoroughly in all sectors such as regulating the on energy efficiency ratios of air conditioner and lightning, installing smart meters to residential buildings and launching awareness campaigns in schools (Kahramaa, 2016b). Thus far, solid reported results of such programs have not been shared with the public in addition to lack of policies or programs focusing on transportation demand management within our knowledge. As a result, this research aims to shed light on these gaps.

Table 1: Various DSM programs in MENA region and some resource-rich countries.

\begin{tabular}{ll} 
Country & Plan \\
\hline Australia & Direct Load Program (Chambers et al., 1990), \\
& Three Tariff Rates in Day (TOU) (Marwan and Kamel, 2010) \\
Algeria & Water Efficiency Program (Shuval and Dweik, 2007) \\
Canada & Demand Opportunity Service, Load Reduction Program (Zareipour et al., 2007)
\end{tabular}




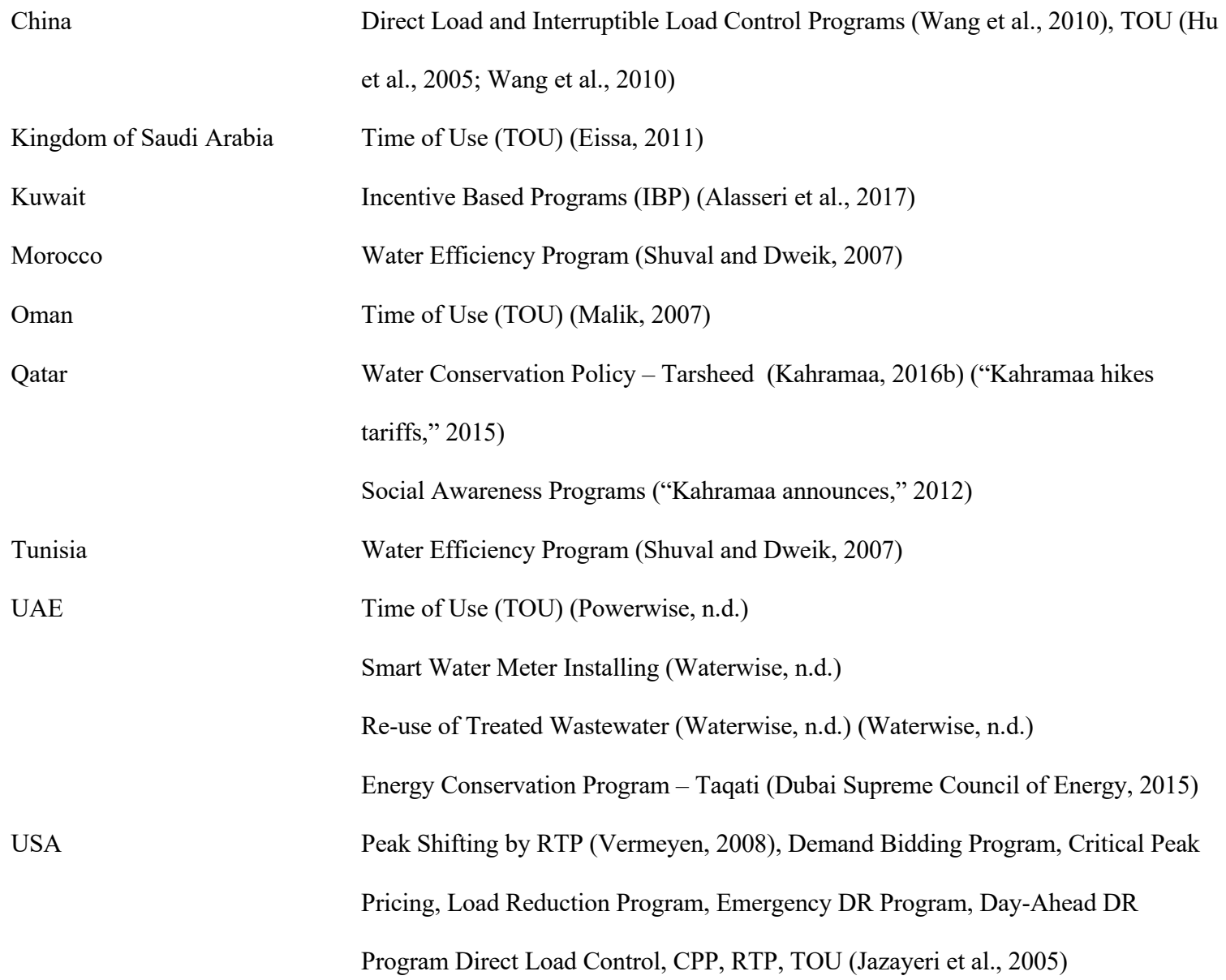

\section{Demand-side Management Framework for Sustainability}

A framework is defined as a system of ideas, beliefs or principles to be used as a guideline in planning, deciding or conducting an action with multiple and interactive dimensions ("framework," n.d.) A framework formed under the concept of DSM would surely serve to the sustainability goals since they perfectly align with each other. As sustainability is not an ordinary concept but rather a historical paradigm, individuals must contribute to the course by changing their regular daily habits and motives, which have been driving them into an unsustainable world. The sustainable lifestyle should be designed for serving sustainability and sustainable development that aim to diminish people's own impacts on carbon footprint and consumption in various sectors. It also should set a goal to reduce the usage of earth's natural resources. As to that, sustainable society is forged from the individuals targeting to live in a sustainable way. Therefore, the need for such policies encouraging people to live in sustainable way, which refers to the DSM policies, is essential for sustainability. Thus, we aim to construct a DSM 
framework that would cover all related fields with sustainable world. A framework for DSM is then an overarching set of guidelines for organizing and specifying the scope, requirements, measures, and limits of DSM. The dimensions determining this DSM framework can be grouped under four main categories: economic, social, environmental, and technical as illustrated in Figure 5. For such an exclusive and broad DSM framework, Qatar's unique dynamics will specifically be explored from various aspects in order to determine whether and how DSM policies would offer potential contributions to Qatar's sustainable development goals for the sectors of energy, water, and transportation. In the light of this framework based on data, information and existing examples from academic, industrial, governmental and non-governmental literature, this study aims to answer how to develop and implement the right set and roadmap for DSM policies in the targeted sectors in Qatar considering its specific dynamics and context.

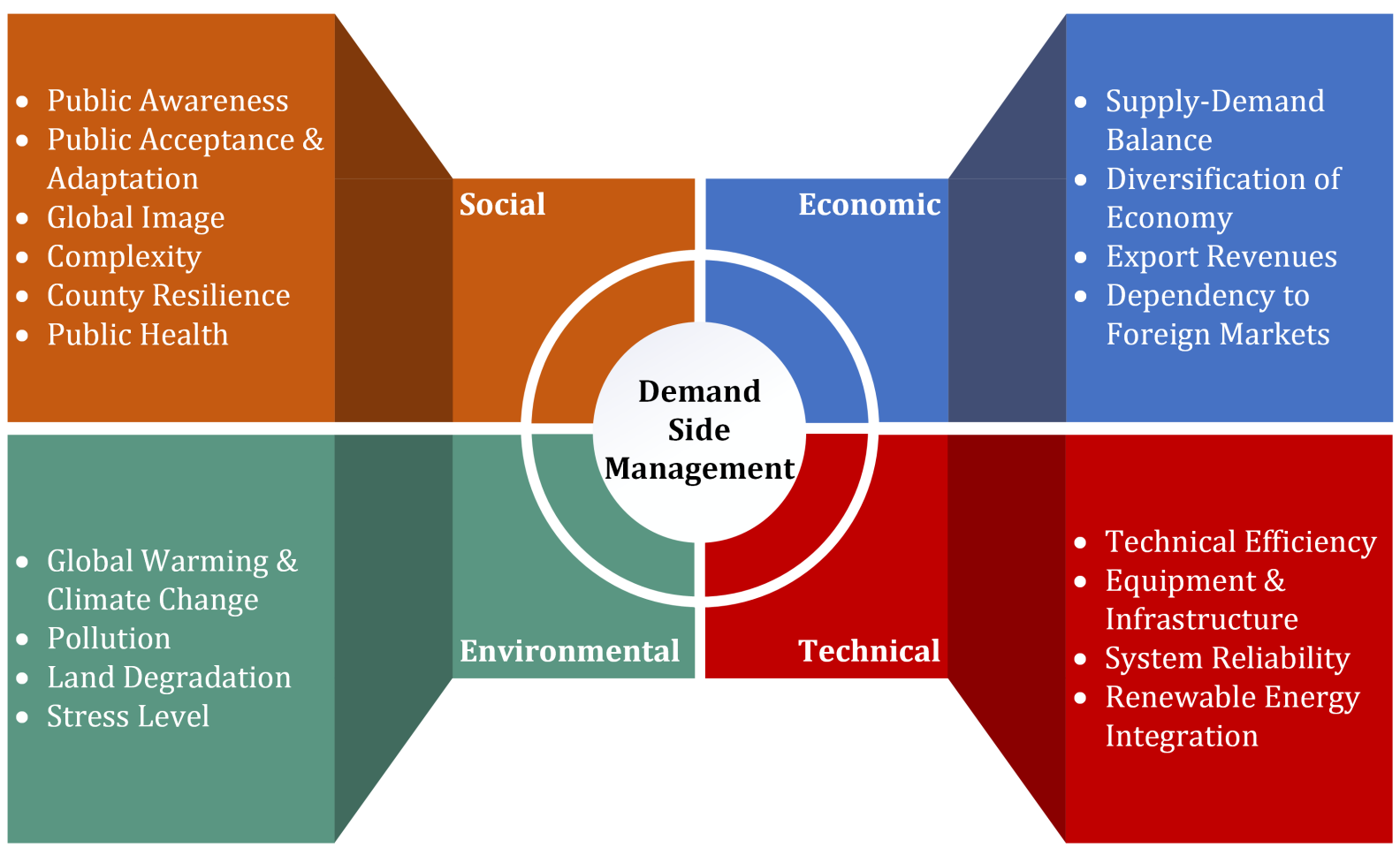

Figure 5. The DSM dimensions classified into four categories. 


\subsection{Economic Sustainability}

\section{Supply-Demand Balance}

As its fundamental definition, supply and demand is "the idea that the price of goods and services depends on how much of something is being sold and how many people want to buy it" ("supply and demand," n.d.) Any flaws or failures in demand prediction would possibly ruin supply and demand equilibrium, which is a great threat to stability and efficiency of economic development. In the context of Qatar, supply has been increasing exponentially in order to meet the increasing demand due to the rapid population growth and over-consumption patterns. For example, in Qatar, water and electricity consumption raised at a rate of $40 \%$ whereas the population growth can reach only $27 \%$ since 2011 (Kahramaa, 2015; The World Bank, 2015). Meeting this tremendous increase in demand required Qatar to spare a significant portion of its budget to considerable investments in infrastructural projects to boost its supply capacity.

\section{Economic Diversification}

In today's world, an economic system, in which only a few sectors are dominant, is seen as extremely vulnerable to external threats resulting from market fluctuations (Mishrif and Al Balushi, 2018). Diversification of economies, in this regard, is critical for the resilience of economies by simply avoiding "putting all of the eggs in one basket". Qatar's economy heavily depends on the hydrocarbon sector (i.e., oil and natural gas), which accounts for $92 \%$ of the country's export earnings and $56 \%$ of the government revenues despite the government's efforts to diversify its economy by investing in steel, fertilizer, and petrochemical industries ("Biggest Natural Gas Reserves," 2013). This situation negatively exposed Qatar to fluctuations in global oil prices, thus indicating that its economic structure is unsustainable and vulnerable to market threats. In parallel to this point, in 2016, Qatar experienced a budget deficit accounting for $9 \%$ of its GDP in 2016, which is the largest by far in the last two decades. With regards to this, considering the role of DSM policies in reducing overall demand, which eventually alleviates the excessive pressure on the energy supply in the country, implementing them would leave more space for policymakers to act more freely in implementing other policies developed explicitly for diversifying 
the country's economy which is already among the objectives of QNV 2030 (Qatar General Secretariat for Development Planning, 2008).

\section{Dependency on Foreign Markets}

Even though the dependency on foreign goods and markets in a country can be diminished entirely by the intorduction of sophisticated production methods and globally interconnected market structures, many nations try to minimize their dependency on specific imports. This is to done to protect the functionality of their domestic markets and more importantly, prevent the effects of any potential crises in international relations, which can affect the conservation of their domestic markets. Unlike many other countries, Qatar does not depend on imports from foreign countries for its energy sector thanks to its abundant natural gas and oil reserves. However, it depends on imports from foreign countries for many other sectors such as machines, electronic equipment, and parts (27\%), metals and raw materials $(19 \%)$, vehicles and transport instruments (18\%), food products $(10 \%)$ and chemical products $(7 \%)$ (Observatory of Economic Complexity, 2017) from the net value of imports is $\$ 31.9$ billion as for 2016 (Observatory of Economic Complexity, 2017). Even if a tiny amount of reduction can be accomplished in these sectors, the impacts on the nation's independence would be huge.

\section{Export}

In order to increase export revenues, there are two primary mechanisms: (1) increasing production capacity; and (2) reducing domestic consumption. Since, liquified natural gas (LNG) is the leading source of Qatar's export revenues with a share of 61\% (Observatory of Economic Complexity, 2017), Qatar announced to investment plans to increase its LNG production levels from 77 million tons in 2016 to 100 million tons by 2024 ("Qatar to boost," 2017). On the other hand, controlling domestic demand is also vital. Electricity and water are produced by using natural gas resources. If the current growth rates continue to exist until year 2024, LNG exports would only increase by $16 \%$ despite the aferomentioned capacity expansion of $30 \%$. To that end, investment for capacity growth would not be successful without establishing a control over domestic consumption. 


\subsection{Environmental Sustainability}

\section{Global Warming and Climate Change}

Longer periods of draughts, more and stronger tropical storms, rising sea level and floods, faster extinction of species, and triggered climate change are some of the potential results of infamous phenomena of global warming (NASA, 2018). According to the World Resources Institute (WRI) (World Resources Institute, 2017) GHG emissions, which is the primary reason of Global warming, are mostly generated from energy sector, -including electricity and heat production, transportation, and manufacturing- which is the main application area of DSM policies. As of 2015, almost $98 \%$ of total Qatar's GHG emissions (109 MtCO2eq.) are from the sectors of energy and industrial processes (Mohammed, 2016). Considering the energy subsectors; oil and gas industry, electricity without industry (domestic, desalination and losses), petrochemicals, metal production, mining, and transport are accounted for $54 \%, 13 \%, 10 \%, 8 \%, 6 \%$, and $5 \%$ of total emissions, respectively (Mohammed, 2016). Despite a two decade long steady population growth, Qatar still ranks the first in the world in terms of GHG emissions per capita. (Global Carbon Atlas, 2018). It is noteworthy that all those emissions figures occur despite Qatar's more efficient production plants compared to the world average (Mohammed, 2016). This means that there is not much room for improvements in supply-side to reduce emissions rate. Thus, DSM policies would be effective to mitigate the impacts of global warmingas defined in QNV 2030 (General Secretariat for Development Planning, 2009).

\section{Pollution}

In the proposed framework, we include (1) air pollution which is caused by construction activities, fossil fuel burning, and industrial activities all of which produces air pollutants such as CO, NOx, SOx, PM2.5, and PM10; (2) water pollution which is caused by unconscious use of urban wastewater, hazardous waste spills, and mining operations; and (3) land pollution caused by deforestation, huge landfills, fast urbanization, and improper sewage treatment. For the case of Qatar, air pollution is a prominent issue among all other pollution types. According to the 2016 WHO report (World Health Organization, 2016a), annual average level of fine PM2.5 particle is of $105 \mathrm{ug} / \mathrm{m} 3$ (critical WHO limit:10 ug/m3 (World Health Organization, 2016b)) in Qatar's urban areas. This figure makes Qatar the second highest 
PM2.5 container in the world behind Saudi Arabia (see Figure 6). Traffic, desert dust, and construction activities are the main contributors of air pollution. Additionally, rest of the pollutants such as $\mathrm{CO}, \mathrm{NOx}$, SOx, and VOCs are notably produced by the energy sector (QatarGas, 2016). Promoting demand mechanisms focused on reducing consumption and usage in electricity, water, and transportation sectors would inevitably decrease the aforementioned contributors of air pollution. In the side of water pollution, there is no risk for fresh water since Qatar's fresh water reserves are already limited and fully utilized in agriculture sector. However, country's oil and gas activities threaten the marine life and quality of sea water which is a provider of many kinds of seafood for Qatar population (Castillo et al., 2016; Freije, 2015).

\section{Land Degradation}

In many megacities across the world; green areas and agricultural lands are rapidly diminishing due to fast urbanization, development of industrial zones, and consumption growth. For the case of Qatar, additional factors such as dead soil and harsh climate reduce green areas, degrade quality of life, and increase accommodation cost. For example, Doha ranks the third most expensive city ("Qatar rents ranked third," 2015) in the world in terms of housing rent and the residents think that the housing is the second most important issue in Doha after traffic congestion (Mohammed, 2017a). Furthermore, in addition to existing large desalination facilities and power generation plants, the projected large PV farms for utilizing solar energy will surely occupy a large amount of land. Hence, lowering demand for energy, water, and personal transportation vehicles would also lower land degradation.

\section{Stress Level}

World population is estimated to reach 10 billion in 2050 (Melorose et al., 2015). According to the calculations made by measuring the ecological footprints of mankind, it will take three Earths to sustain the population in 2050 if the consumption trends continue ("Carrying Capacity," 2016). To this end, the UN suggested that mankind drastically need to change their consumption patterns which put a strain on the environment and natural resources (Dr. Edward Spang, 2009). In terms of electricity consumption per capita, Qatar ranks fifth in the world (see Figure 7) while in terms of energy-based water 
consumption per capita, Qatar comes first in the world (see Figure 8). To that end, it is critical to lower stress level by conservation of resources.

\subsection{Technical Sustainability}

\section{Technical Efficiency}

Efficiency is defined by IEA as "low-hanging fruit" due to its great potential generated from its low marginal cost (International Energy Agency, 2010). From Qatar's perspective, improving efficiency within economic, social, and environmental systems has been already referenced multiple times in QNV 2030 (General Secretariat for Development Planning, 2009). In the light of this vision, with the production and economic boost in last decades, the systems have become sophisticated and efficient; the quality of products and equipment have been increased. On the other hand, escalated population and consumption levels exerts pressure on making systems more efficient in addition to already made public investments. Ever-increasing demand is capable of wiping out the benefits offered by efficiency due to the "rebound effect". Thus, the success of the efficient system ultimately depends on the controllability of demand. DSM applications can offer various remedies such as popularizing the usage of efficient products by influencing the population, making existing systems and infrastructures more efficient by lowering demand, avoiding unnecessary investments, and giving supply developers and providers elbow room by reducing the continuous pressure on efficiency boost. 


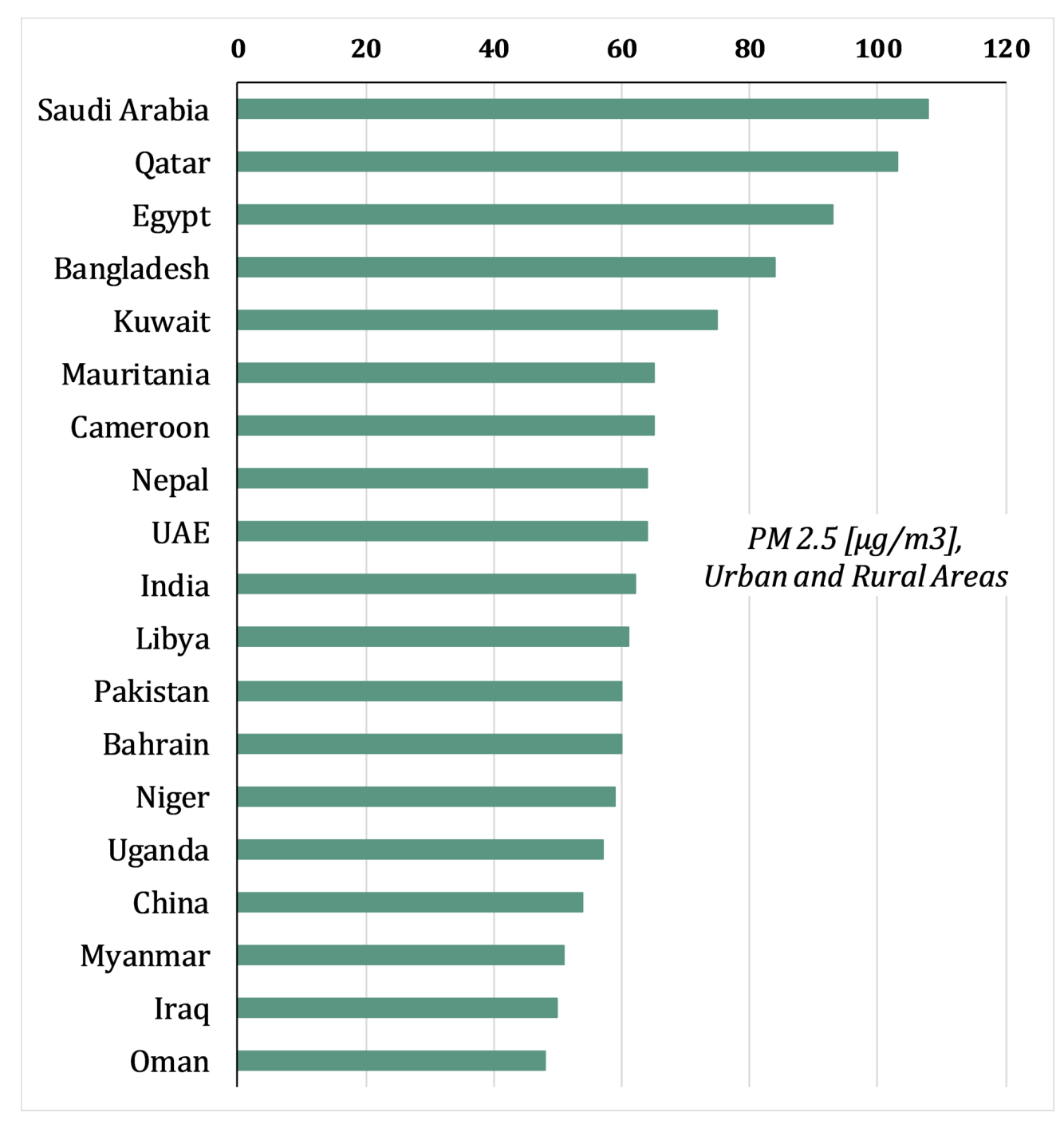

Figure 6. The countries that have the largest annual median concentration of PM2.5, population-weighted and modeled (World Health Organization, 2016a). 


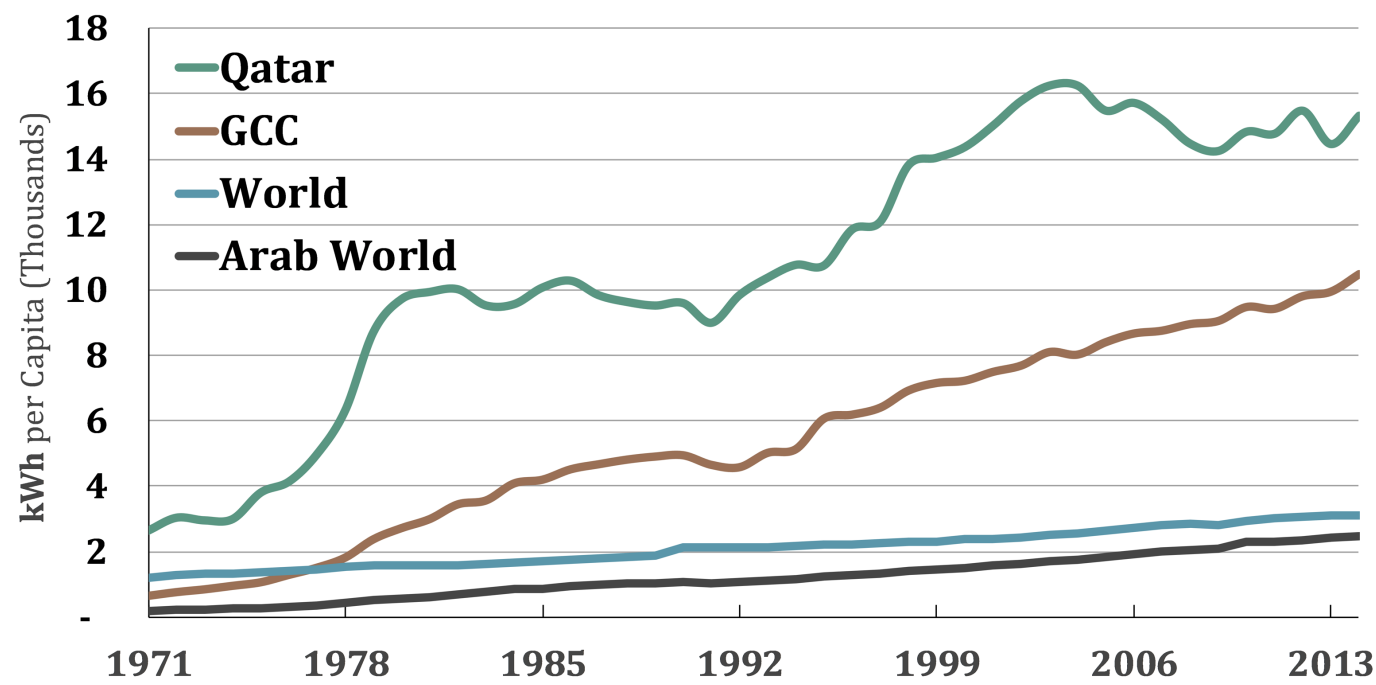

Figure 7. The annual electricity consumption per capita ( $k$ Wh) of selected countries in the world (World Bank, 2018d).

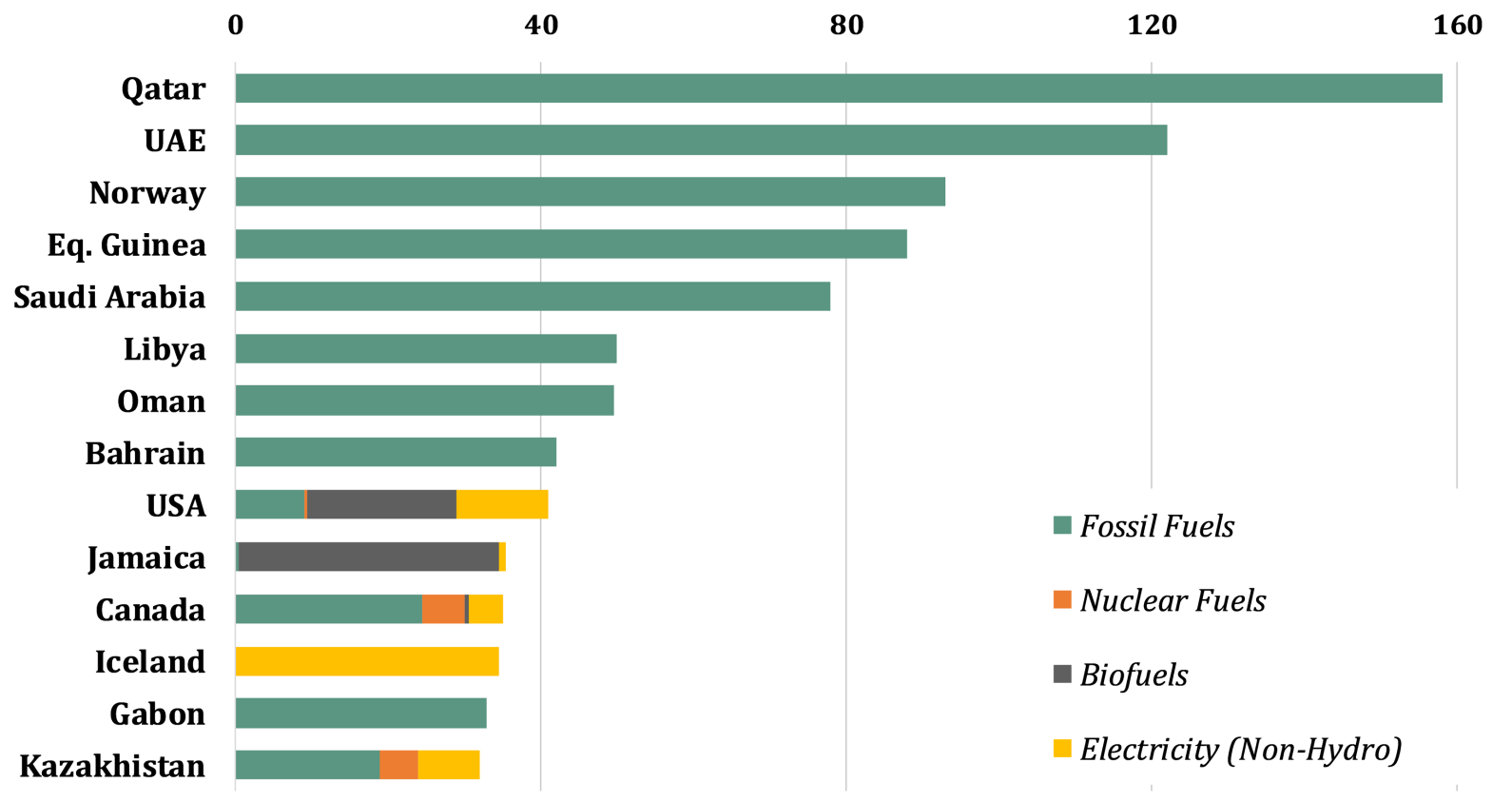

Figure 8. The energy-based annual water consumption per capita (m3/person) of the countries (Dr. Edward Spang, 2009). 
Some DSM application require specific equipment or infrastructure to be successfully implemented. These equipments are typically used for monitoring, sensing, and communication purposes. For instance, smart meters and energy monitors are used to to accurately monitor consumer's consumption, provide feedback to customers or even directly control appliance usage. Similarly, road tolls are used to nudge people to change their travel behaviors. Since Qatar's economic development took place during last decades, its key infrastructures such as electrical grid, water distribution systems, and road transport systems are relatively young and modern when compared to the infrasturcutures in the western world (Bayram and Mohsenian-Rad, 2016). From this perspective, Qatar stood in a good place to be able to employ DSM policies successfully and run them in the most efficient way. Furthermore, in the electricity sector, according to Kahramaa, 17,000 smart meters will be deployed in the housings in Doha in order to monitor the electricity consumption of residents (Abdulla, 2015). Even though they are being used for only reading the consumption remotely -not for promoting any conservation programs- it is still an improvement to provide timely feedback to customers on their consumption levels. With the completion of those investments and existing infrastructure, DSM policies will be able to operate thoroughly for the purpose of modifying consumption patterns of Qatar population. Another option would be to install Internet of Things (IoT) based home energy management systems which are less costly than industrialgrade ones. Such can be highly effective to reduce consumption patterns, especially for residential electricity usage (Risteska Stojkoska and Trivodaliev, 2017). A demonstration project in Qatar is presented in reference (Bayram et al., 2019).

\section{System Reliability}

The most desired systems are usually based on their ability to function error-free or very few errors and regardless of the sector, the fluctuations in demand would affect the system in an undesired way. Sudden increases in the electricity demand, for instance, would likely to cause power shortages. In another example, in case of an important event, an increase in overall water demand would diminish the storage of water. Regarding the electricity supply, despite new and advanced grid systems and huge investments on expanding supply, there still are unexpected blackouts lasting a day in Doha which makes the life of the residents harder ("Power failure at Pearl," 2016; "Unexpected power outage," 2016). Likewise, in 
terms of transport, through constant investments on the transportation system, in 2016, Qatari residents spend extra 109 hours due to traffic congestions which costs \$6 billion to Qatar economy according to the Qatar Mobility Innovations Center (QMIC) (QMIC, 2017). Due to the harsh climate of the country and irregular population alterations over the year, the demand can unexpectedly fluctuate which cause the aforementioned problems during supplying resources. DSM policies could help supply systems be more reliable and organized by encouraging people to shift their consumption and flattening the demand.

\section{Renewable Energy Integration}

Renewable energy systems such as photovoltaics and wind tribunes aim to provide cleaner energy and contribute to achieving sustainable development. However, those systems create energy storage issue because the time span of energy production and consumption are not perfectly aligned. Qatar is making significant investments on renewable energy in order to diversify its energy supply sources. As a first step, Qatar is deploying 350 MW solar PV plant by 2020, and the capacity will be expanded to 700 MW ("Large Scale Solar Power Plant," 2018). With those investments, the share solar energy in electricity generation is expected to reach $20 \%$ by 2030 ("Solar Energy to meet," 2016). Hence, the integration problems of renewable energy to power sources would likely to accompany the rise of the share of renewable energy. Herein, demand-side policies would be valuable asset to provide a smooth transition from conventional resources to renewable resources. Furthermore, the investments on the storage facilities power grids seriously need, can be compensated with shifted demand hours provided by DSM policy (Pina et al., 2012).

\subsection{Social Sustainability}

\section{Public Awareness}

Implementing a social policy requires human factor to be considered both for prior to and following its implementation. As DSM targets people in order to adopt more sustainable behaviors, the success of any DSM programs highly depends on how much the participants of the DSM program are aware of the goals, motives and anticipated outcomes of the program. According to a survey conveyed in Qatar in 2016, it is observed that the residents have a high awareness of potential and current issues of Qatar such 
as climate change (96\%), sustainable development $(89 \%)$ or ecological footprint $(80 \%)$ (Mohammed, 2017b). Moreover, they affirm that environmental issues are the result of man-made actions (91\%) and they are willing to restrict their consumption behaviors to protect the environment (88\%) (Mohammed, 2017b). On the other hand, the majority of the attendants complain about the lack of policies, advertisements of initiatives and campaigns, laws and regulations to ensure citizens and industries participating the environment protection (75\%-94\%) (Mohammed, 2017b). At this juncture, since Qatar population has already had a certain amount of awareness, the country can be considered as lucky to implement DSM policies that can be seen as a supporting tool to build an environmentally aware society, which is one of the strategies (goals) set in Qatar National Development Strategy to protect the environment for future generations (Qatar General Secretariat for Development Planning, 2011).

\section{Global Image}

In today's global world, the results of any country's actions -especially on the environment- should equally concern the rest of the world. Therefore, global image of a company, as well as a country, is highly essential for their financial sustainability as people (or consumers) judge them from economic and development aspects as well as from environmental and social aspects. For instance, the reputation of the U.S. has declined specifically after the withdrawal from the Paris Climate Agreement (The Atlantic, 2018; The Washington Post, 2018). In other examples, the prestige of large corporates British Petroleum (BP) and Volkswagen has been negatively affected after the scandals of "Deepwater Horizon" oil spill and "Dieselgate" emissions measure deception, respectively (Alva Group, 2015; "Five Years After Deepwater Horizon," 2015). Despite its relatively small population and land area, Qatar has managed to be in front of the world's eyes with several characteristics such as wealth, being the host country for the 2022 FIFA World Cup and its notorious economic activities in the western world. On the other hand, Qatar is also known for its high consumption patterns in terms of $\mathrm{CO} 2$ emissions per capita, electricity usage, water usage, food waste, etc. Along with these, its hydrocarbon-based economy threats its global image in the long term. Moreover, the policies on supply-oriented policies are overwhelmingly centralized as the national focus, and not much solid policies from demand side are 
promoted. Having a strategy that contains reducing overall consumption by modifying people consumption patterns would gorgeously serve to the reputation of the country.

\section{Public Acceptance \& Adaptation}

Apart from public awareness, the response from the society towards a newly implemented policy is also important. People either prefer to adapt to the policy which affects their lifestyle or refuse to follow the policy instructions. Along with public acceptance; high public education level is another element to increase the public adaptation by not only making the society more sensible but also having them to comprehend more complex policies like DSM. In Qatar, as the society has been witnessing rapid development in the country in the last decades, they are accustomed to the adaptation of many newly introduced policies, projects, and programs, which targets their lifestyles from many different angles. Thus, these high levels of public acceptance and adaptation poses no signs of public resistance. This can be seen as an excellent opportunity for successful implementation of DSM policies, especially by considering the fact that people of Qatar already stated their willingness to make sacrifices in their 'excessive consumer lifestyles' to contribute to the environmental protection (Mohammed, 2017b). Furthermore, with their education systems outlined as world class (World Economic Forum, 2018) and willingness, Qatari residents seem to be ready to easily adapt to a new policy altering their lifestyle.

\section{Complexity in DSM application}

Regardless of how comprehensive the policy is, its complex structure may lead to failures in the systems that requires user participation. In some DSM programs, participants are instructed to perform multiple tasks at the same time. Although Qatar population can be considered to have a good level of education, participating in complicated systems and programs can be difficult. Besides, considering the wealth and the usual comfort of local people, high intricacy of policy would discourage them to change their consumption behaviors. As a result, aside from being beneficial to society, DSM policies being not welladjusted complexity may be even harmful.

\section{Public Health}


Despite considerable advancements in healthcare and medicine sectors, the share of people with any kind of acute or chronic diseases has reached $95 \%$ of the world population (Institute of Health Metrics and Evaluation, 2013). According to the WHO, in order to reduce the impacts of the factors behind new diseases caused by lower air quality, polluted water and sea, lack of activity, and urbanization, people are required to change their behaviors by adopting more sustainable lifestyle, especially reducing their consumption levels in order to prevent the problems from worsening. As of 2017, Qatar allocated \$6.7 billion, 12\% of the total expenditures ("Qatar's 2017 budget," 2016), to its healthcare sector with the average annual rise of $15 \%$ since 2008 (Alpen Capital, 2016). Despite those investments, according to the Qatar Biobank Report (Qatarbiobank, 2017), more than 70\% of the population in Qatar, which is the highest in the GCC (Alpen Capital, 2016), belongs to the overweight and obese categories due to lack of physical activity. In another study conducted in 2006 (Janahi et al., 2006) found that $20 \%$ of pupils in Qatar has asthma which is likely to reach higher figures than the past due to rapid urbanization, constructions, and population growth since 2006. These facts are parallel with some other statistics such as having the second highest level of dangerous air pollutants PM2.5 and PM10 or 800 cars per 1000 person (Qatar Planning and Statistics Authority, 2017). As a result, Qatar has serious public health issues related to citizen's current lifestyles associated with over-consumption of multiple resources. Employing DSM policies that aim to encourage people walking or consuming less, for instance, would contribute to improving public health.

\section{Country Resilience}

Apart from dependency mentioned in earlier dimension, any country can face various kind of risks that threats its economy, stability or even sovereignty. Qatar is located in the middle-east region in which natural or human-made risks and threats such as conflicts, hostilities, droughts, famines that make the living conditions difficult have always been taking place not only in this century but also the wide course of history. In addition to those risks, having a large amount of natural resources may also contribute to the bitter rivalry among its neighbors about being a soft power in the region. One of the examples of those threats has been witnessed in the embargo enforced in June 2017 ("Qatar Crisis," 2017). Those economic, politic and geographic reasons put the country in a vulnerable position. Thus, 
to be resilient in the face of various threats and risks, just as government, society must also have the capability to endure the life-changing impacts of those threats. To this end, under the scenario of successful implementation of DSM in Qatar, two possible outcomes would likely occur to support the country's resilience status: (1) The government would have greater sources to sustain the aids (incentives, subsidies, tax cuts, etc.) in order to alleviate the impact of the crises with the already reduced consumption. (2) The residents of Qatar would have already been changing their consumption habits and trying to reduce their overall consumption by themselves.

\section{Survey Study and Set up}

The survey study has been conducted to take a snapshot of Qatar Residents' perceptions and attitudes on the potential DSM policies and sustainability goals. Survey methodology is a common research technique, which consists of data collection from a sample of elements drawn from a defined population mostly through a questionnaire generated for different purposes (Barker et al., 1989).

\subsection{The Survey Area and Focus}

The questionnaire was designed based on fruitful discussions with various members of faculty and researchers at Hamad bin Khalifa University, Qatar Foundation and Education City in Doha. The survey was conducted in greater Doha, Qatar, where $92 \%$ of the country's total population resides (Ministry of Development Planning and Statistics, 2017). The target population of the survey includes people with an age of 18 years or older and live in residential housing units in Doha during the survey reference period; and excludes those who live in institutions such as army barracks, hospitals, dormitories, and prisons. Over a half of the questionnaires (250) were published online while the rest is distributed as hard-copy among 490 randomly chosen residents. The response rate reached nearly one hundred percent for the face-to-face interviews and $60 \%$ for the surveys conducted online. Furthermore, the accepted sample size for populations more than one million should be at least 384 (Cohen et al., 2007) with a confidence level of $95 \%$ and $5 \%$ error rate; therefore, we believe that the number of respondents in our survey is reasonable enough to represent the target population. 


\subsection{Validity of the Survey}

Validity techniques that ensure the accuracy of a survey covering what the questionnaire initially intends to measure can be classified into two categories (Bolarinwa, 2015): (1) for internal validity issued with the questions designed with the help of researchers, who have expertise in the relevant subject. and (2) external validity issued with some randomly chosen participants since the target population was chosen as all adults residing in Qatar rather than a specific group of people. Moreover, in order to improve the validity and reliability, a pilot test with interviews was conducted among twenty randomly selected participants prior to the actual spreading of the survey. According to the feedbacks, the questionnaire was improved to its final version. Finally, the post-survey interviews with the experts in the fields have been done in order to get further analysis about what might be the possible interpretations of the survey results.

\subsection{Conceptual Model}

As shown in Figure 9, the survey is comprised of three main sections as follows:

1. Social and demographic questions (4 questions).

2. The questions evaluating the awareness level of the participants and their understandings towards the sustainability and environmental issues in Qatar and revealing the participants' resource consumption patterns in terms of electricity, water, and transportation (29 questions).

3. The questions measuring the level of participant's willingness to adapt the potential DSM policies (23 questions).

The questions were generated in three different types; (1) Multiple choice, which aims to reach exclusive information of the participants such as age, income, and education or to understand their perception based on their knowledge and opinions on different subjects; (2) Rating, which aims to obtain what level the participant agrees to the statements given; and (3) Checking/Marking, which has been used for two different purposes; checking all options that apply or selecting up to three option(s) which is/are counted as the most prominent among all options by the participants. 


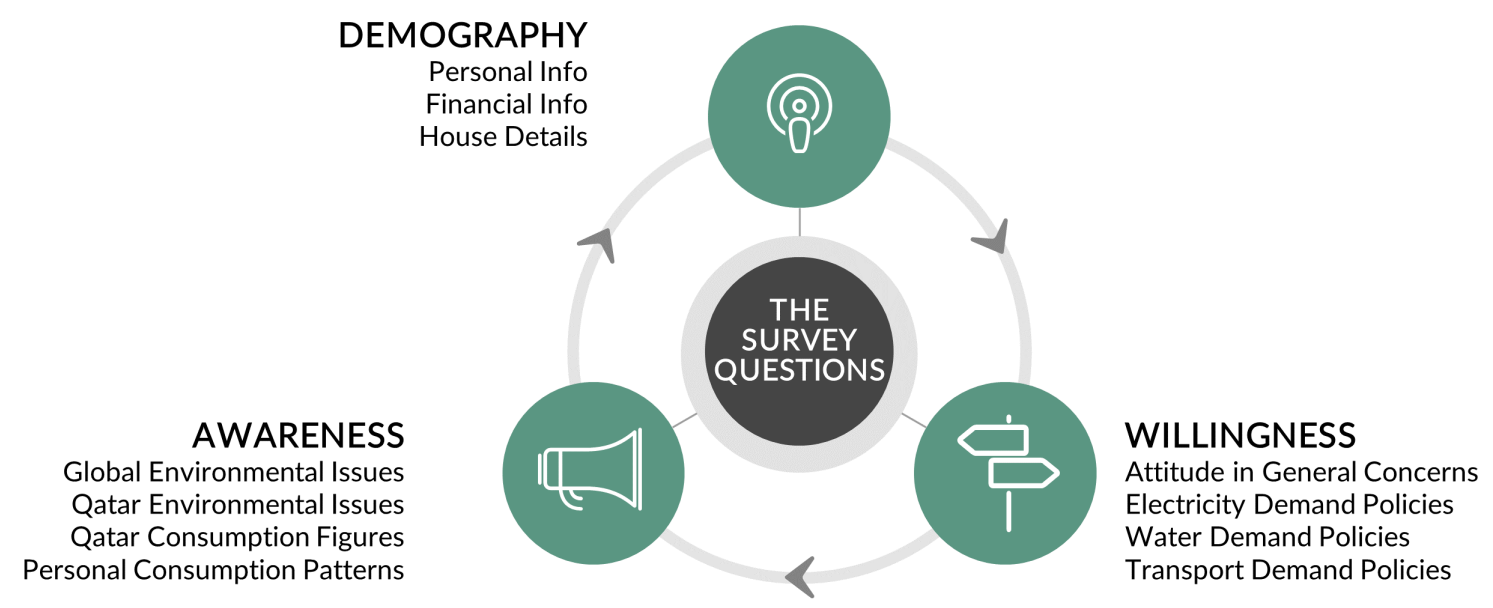

Figure 9. The sections of the questionnaire.

\subsection{Interpretation of Results}

Apart from the results of demographic characteristics, the majority part of the questions was interpreted one-by-one in the discussion section since most of the questions were asked to reveal the perception of the population. During the evaluation, directly, percentages are given as how many percents of the participants choose the answer right. For the few questions asking how likely the respondent agree on the statement, the interpretation is made with the percentage of total "agree" choices ("strongly agree" and "agree") or "disagree" ("strongly disagree" and "disagree") choices are provided to illustrate the attitude of the society.

\section{Survey Results and Discussion}

\subsection{The Representativeness of the Survey}

The total number of respondents was 390, 14\% of which were Qataris. This makes the sample a good replicate of the overall population as Qataris constitute around 12\% of the total population of Qatar. Regarding the gender, nationality, age groups, income ranges, and education level, the characteristics of the respondents are as follows:

- The percentage of gender is distributed evenly by $50 \%$.

- The shares of the nationality, as shown in Figure 10, are Asian (30\%), Middle-Eastern (24\%), Qatari (14\%), African (13\%), European (10\%), and American (6\%). 
- The shares of age groups are 18-23 (16\%), 24-30 (35\%), 31-40 (32\%), 41-50 (13\%) and more than $50(4 \%)$.

- The shares of income groups are (QAR) less than 10k (48\%), 10k-25k (26\%), 25k-50k(17\%), 50k-100k (8\%), more than $100 k(1 \%)$.

- The shares of education level, as shown in Figure 10, are; primary or lower education (1\%), secondary (6\%), post-secondary (8\%), university/college (44\%), and master/Ph.D. (43\%).

In Qatar, as of 2016, the distribution of various age groups of Qatar is 18-23 (11\%), 24-30 (28\%), 31-40 (33\%), 41-50 (18\%), and 50+ (10\%) (Ministry of Development Planning and Statistics, 2016). The survey has managed to capture a good representative of the actual population in terms of age groups (Figure 12). For income level, the sample is sufficiently representative to capture the statistical distribution of the population. This is depicted in Figure 11.

However, due to lack of information, we cannot examine the representativeness of the survey in terms of education level. Besides, the nationality and gender distributions of the survey seem not to correspond with the actual population statistics. The main reason is that the population is not normally distributed in terms of gender and nationality because almost all of the blue-collar labor force is young males from South Asian countries who live in remote labor-camps in Qatar with minimal control on their resource consumption such as electricity, water and transportation. Hence, when they are excluded from survey consideration, the gender distribution becomes be $51 \%$ for females and $49 \%$ for males, which are the right figures for the rest of the population and what the survey captured. Finally, $92 \%$ of the respondents have been residing in Qatar for more than one year, which makes the results more accurate since the study focuses mainly on the habits. As a result, it can be claimed the survey successfully represent the whole population in terms of gender, income level, age, and nationality. In addition, the survey was offered in two languages, English and Arabic, which are prevalently spoken among the population when blue-collar workers are excluded from the survey consideration.

Regarding the statistics on the number of household members, $9 \%$ of the respondents live alone, $51 \%$ of the respondents have $2-4$ household members, $31 \%$ of the respondents has $5-8$ household members, and $9 \%$ of the respondents have $8-12$ household in the house. The average number of house-members 
of the survey is 4.57 which is entirely accurate with the actual statistic (4.75) (Ministry of Development Planning and Statistics, 2016). For the type of housing units, about half of the participants (48\%) live in flats while $46 \%$ live in villas. Besides, as quite parallel with the survey results, the actual data for the percentage of the population who live in flats is $38 \%$ while in the villas is $51 \%$ (Ministry of Development Planning and Statistics, 2016). Therefore, survey fairly represents the whole population in terms of an average number of residents in flats (house-member) and villas and the percentage of residents who live in flat and villa (housing type) (Figure 13).
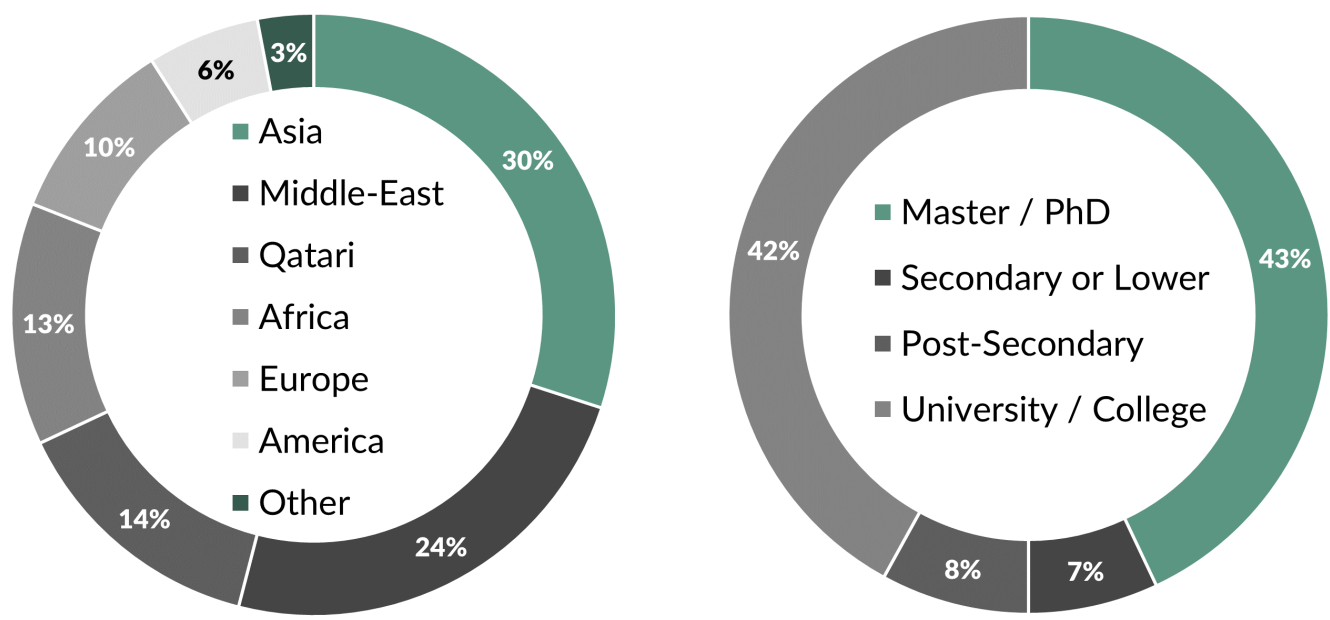

Figure 10. The distribution of the nationalities of participants (left) and the education level of participants (right). 
Figure 11. The representativeness of the sample in terms of income level.
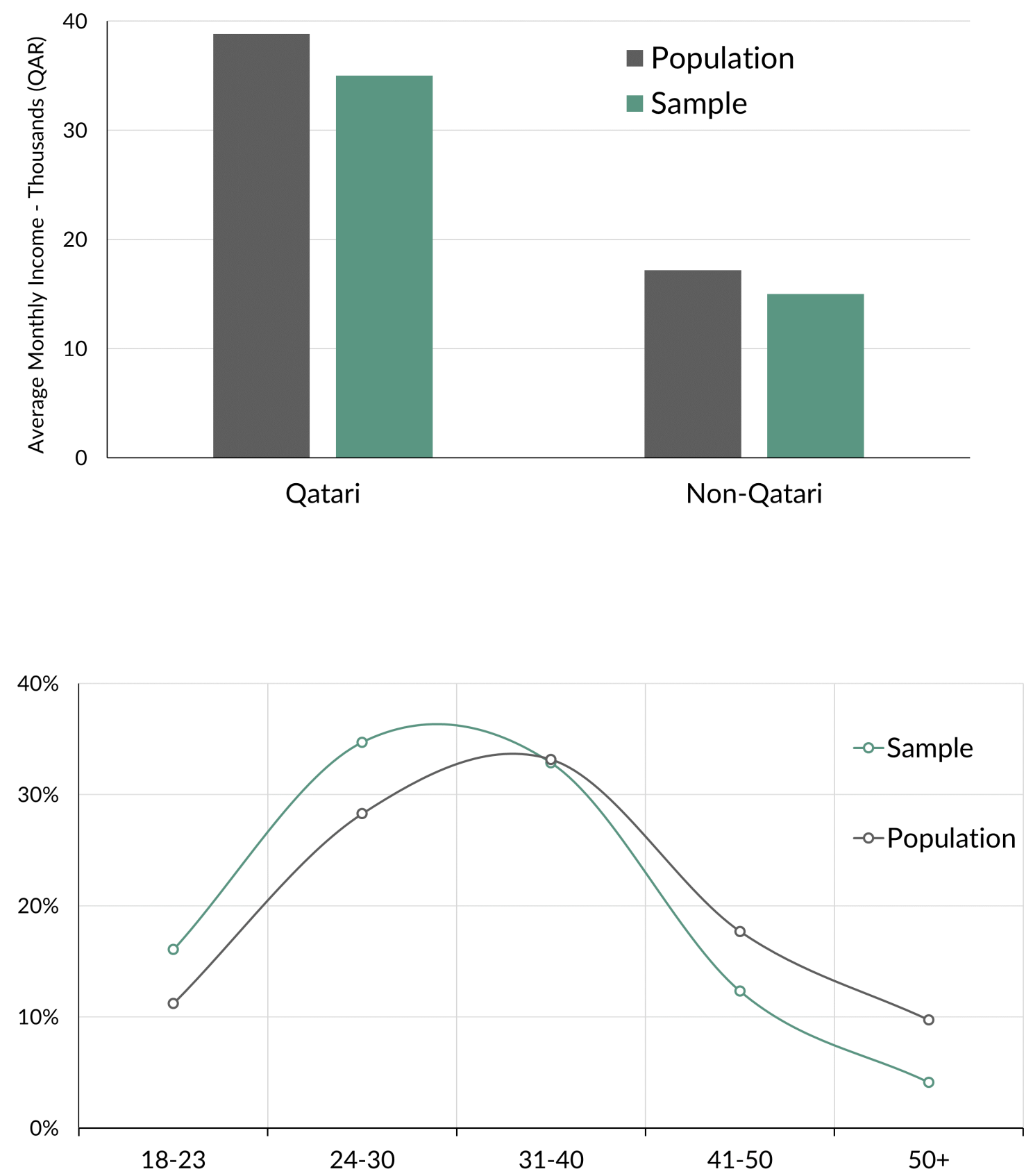

Figure 12. The representativeness of the sample in terms of age groups. 


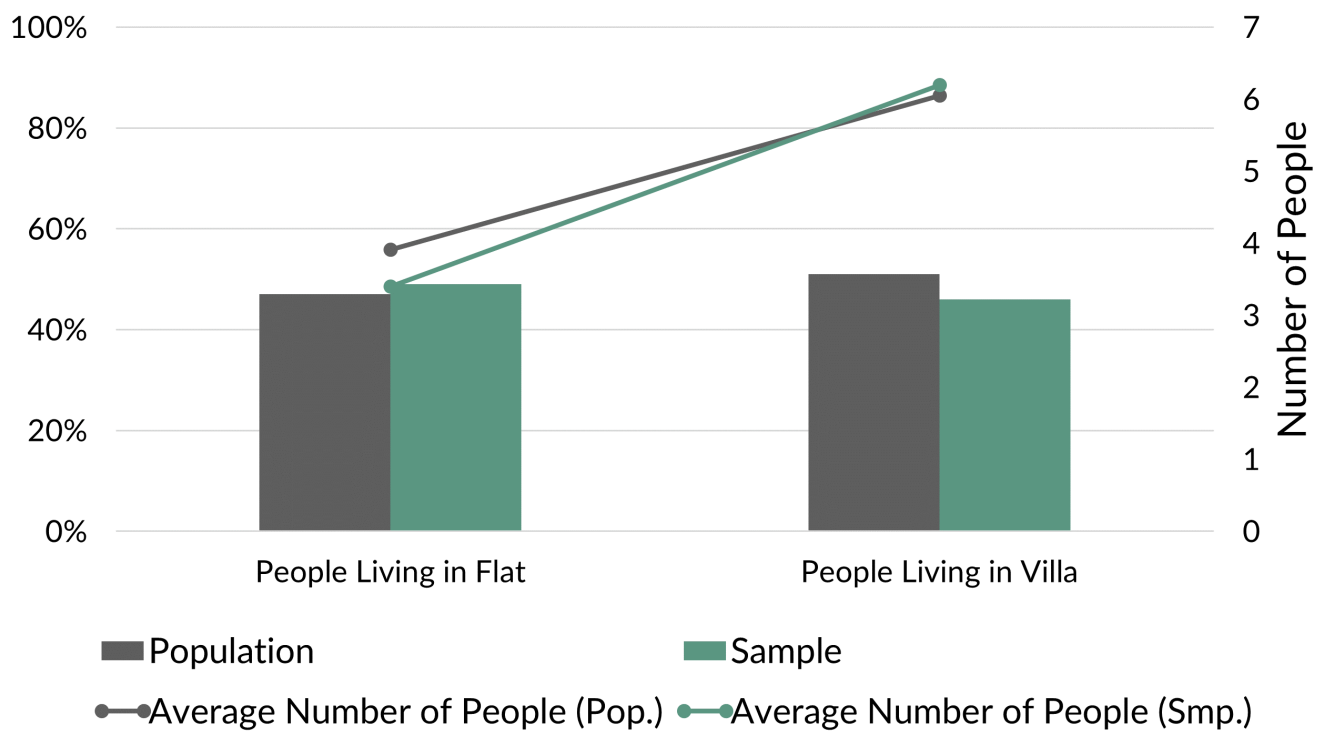

Figure 13. The representativeness of the sample in terms of house-members and house-types.

\subsection{The Awareness Level of the Residents of Qatar}

In the survey, the participants were asked to rate or choose from the various type of questions in order to capture their perception and awareness on the subject of global environmental issues, Qatar's environmental issues, and their consumption patterns.

Regarding the awareness of the global environmental issues, Table 2 tabulates the environmental terms heard the most by the participants, the motivations of the participants for protection of the environment and the most impacted concerns by the participants' consumption patterns. Some prominent results are highlighted in Figure 14. More than half of the respondents' rate air quality and global warming/climate change as the most impacted concerns, and, water security and national security as the least impacted concerns by their consumption patterns. In lined with the reality (Kahramaa, 2016a), the respondents consider air conditioning as the most consumer of electricity with a share of $95 \%$; and shower activity as the most consumer of water. Lastly, their perception on best way to transport is illustrated in Figure 14.

Regarding Qatar's environmental issues and limitations, as summarized in Figure 15, air pollution, global warming and resource depletion are regarded as the most serious environmental issue Qatar is facing while the issues such as water pollution, land degradation, and the loss of biological diversity 
(21\%) are seen as the least serios. Additionally, the most responsible entities and the most important urban issue perceived by Qatar population is provided in Figure 15.

When the respondents were asked the questions about specific subjects, it was observed that they had a significantly apparent lack of knowledge. Although they identify themselves as well informed on Qatar's resource limitations and figures with 57\%; the percentages of correct answers in the questions linked with those figures are so low in various subjects such as $\mathrm{CO}_{2}$ emissions per capita ranking in the world $(24 \%)$, electricity consumption per capita ranking in the world (22\%), remaining days for fresh water storage (24\%) as presented in Figure 16. Increasing the share of people who are aware of those figures by awareness campaigns as a part of DSM policies would nudge people to reduce their consumption. On the other hand, the respondents are sufficiently aware of Qatar's primary source of electricity ( $59 \%$ - natural gas) and water ( $84 \%$ - desalinated seawater).

Regarding the participants' consumption and usage patterns of the resources, they identify themselves $(47 \%)$ or other family members $(24 \%)$ as main user/controller for the water and electricity consuming activities and appliances in the household. This make the potential policies developed from this research would refer to the legitimate audience. However, majority of the participants $(73 \%)$ indicating that they do not pay their bills for electricity and water themselves, and therefore do not know their spending (58\% for non-Qatari, $80 \%$ for Qatari), would surely reduce the potential effects of demand-controlling policies specifically PBPs or other price-oriented policies. People who do not pay but know their bill are the ones whose families pay the bills for them. Within the rest, the average monthly electricity bill amount for summer is 225 QAR in winter and 460 QAR in summer; and the average monthly water bill amount is 243 QAR. Additionally, we calculated the average bill/income ratio, 4.58\%. For comparison, average electricity bill/income ratio is $2.15 \%$ in US where price-based policies are widely implemented and being successful ("Percentage of Income on Electricity," 2015). Thus, we can conclude that in practice, Qatar society can respond positively to the price-based policies if they know their consumption as well as spending, but certain policies such as government incentives we touched upon in introduction, become an obstacle on the way towards success. Despite the fact that more than a half $(52 \%)$ of the respondents keep their air conditioning (AC) level at $22-24{ }^{\circ} \mathrm{C}$, and $36 \%$ keep at $18-21{ }^{\circ} \mathrm{C}$; they usually turn off the AC for different occasions such as during cold months or nights (72\%), when nobody is 
home (55\%), on vacation (57\%) and partly in some rooms (56\%). Only 7\% of the participants stated that they never turn off the AC. Since the AC is the primary source of electricity consumption, these responses look promising to implement efficiency demand policies such as installing smart devices that control the AC remotely. Within the $73 \%$ of the population that has a vehicle, $40 \%$ e drive $11-30 \mathrm{~km}$ daily and $21 \%$ drive averagely $31-50 \mathrm{~km}$ daily. Almost all of the vehicle-owners know their oil spending; 451 QAR averagely per month. High awareness of oil spending could set a good starting point to implement a DSM policy for transportation. For example, car sharing applications might get incentives or cheaper oils, and cheap and broad public transport could be promoted in long term. The percentage of the participants that never use public transport is as high as $73 \%$ which seems a serious barrier to pass over in order to implement policies depending on encouraging people to use public transport. Of all reasons preventing them from using public transport, the public put inconvenient schedules to the top of the list with long travel times and lack of rail systems. Finally, participants stated private car $(82 \%)$ by far as their primary mode of transportation in Qatar while rail systems (51\%), public road transport (49\%), and taxi (45\%) as the primary mode of transportation in outside of Qatar. These results also show that the society do not prefer public transport not because they have strong negative opinions about preferring public transportation (because they use it abroad), instead, because they have settled habits and some specific concerns. Thus, eliminating those concerns and nudging them to change their habits would encourage them to use public transport more instead of private cars, which would benefit to environment, public health and economy.

Table 2. The answers in the order obtained from the participants regarding some questions.

\begin{tabular}{|c|c|c|}
\hline $\begin{array}{l}\text { Environmental terms } \\
\text { heard or familiar the most }\end{array}$ & $\begin{array}{l}\text { Motivation to be concerned about or to } \\
\text { protect the Environment }\end{array}$ & $\begin{array}{l}\text { The most impacted issues/concerns by the } \\
\text { consumption patterns of the respondents }\end{array}$ \\
\hline Global Warming (90\%) & Moral \&Ethical Values (55\%) & Air Quality (44\%) \\
\hline Water Pollution (89\%) & Laws and Regulations (52\%) & Global Warming (43\%) \\
\hline Renewable Energy (86\%) & Awareness Campaigns (40\%) & Water Scarcity (42\%) \\
\hline Sustainability (84\%) & Responsibility for Earth (37\%) & Resource Depletion (41\%) \\
\hline Resource Depletion (81\%) & Rights for Future Gen. (36\%) & Energy Security (40\%) \\
\hline
\end{tabular}




\begin{tabular}{lll}
\hline Food Security (76\%) & Religious Values (35\%) & Food Security (37\%) \\
Air Quality (75\%) & Cultural \& Social Norms (27\%) & Water Security (26\%) \\
Equality/Inequality (72\%) & & National Security (16\%) \\
\hline
\end{tabular}

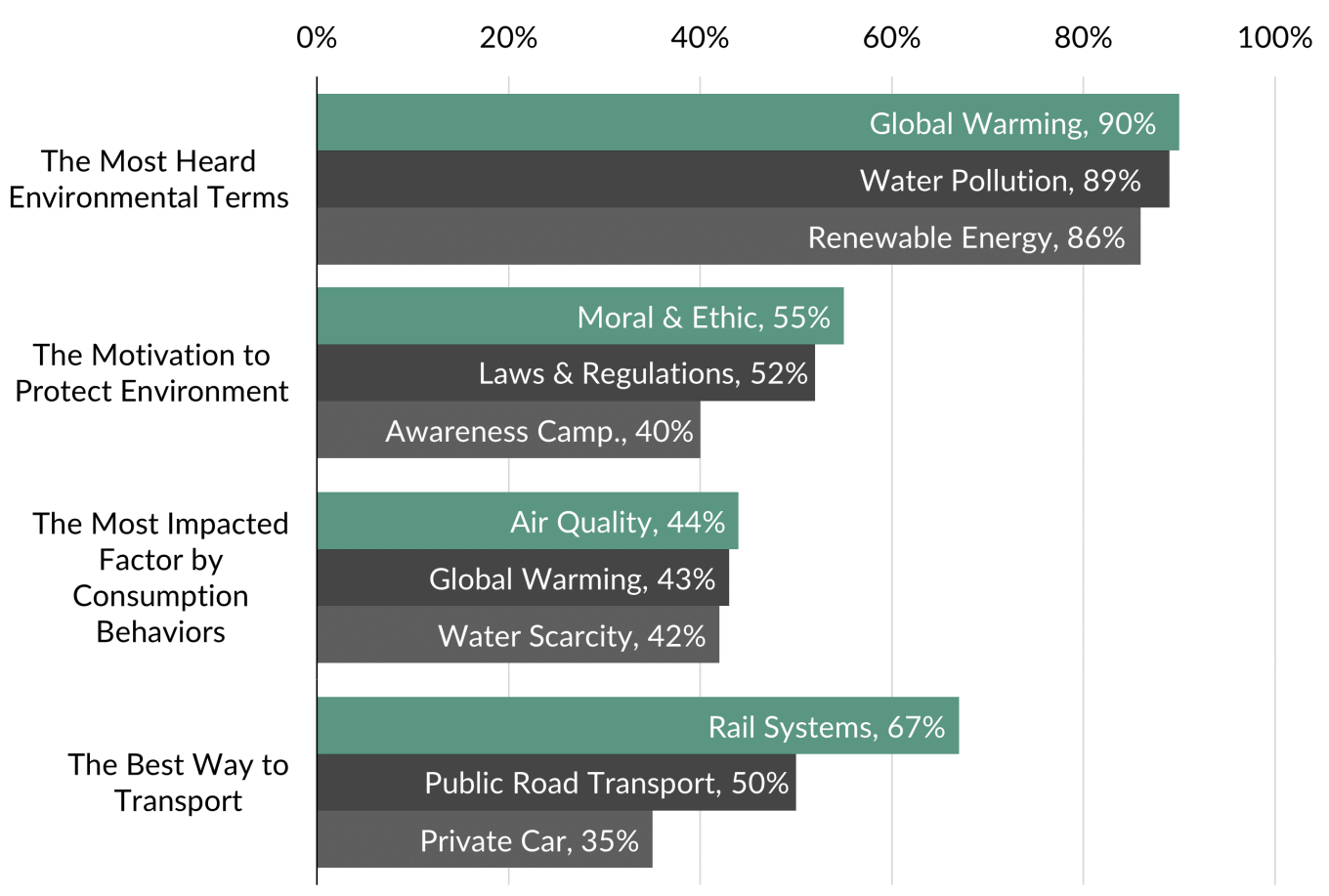

Figure 14. Some featured results of the questionnaire on global issues. 


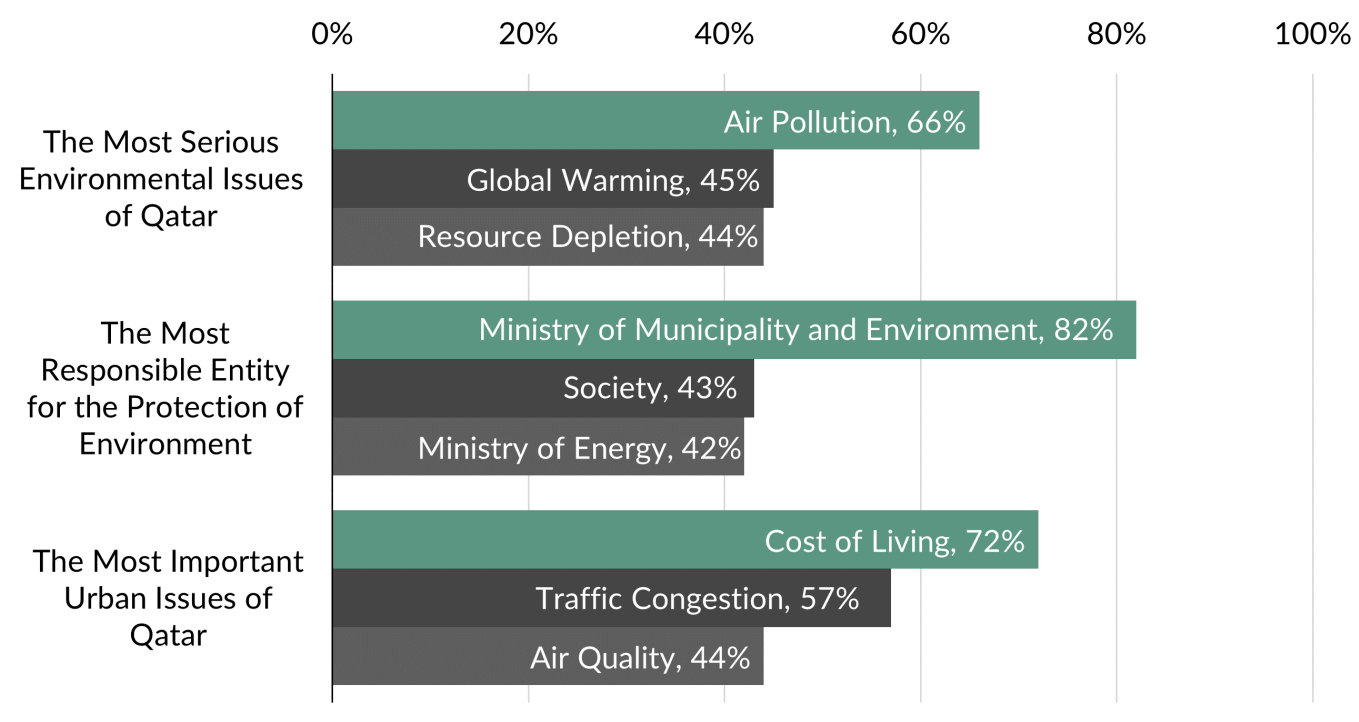

Figure 15. Some featured results of the questionnaire on Qatar's problems.

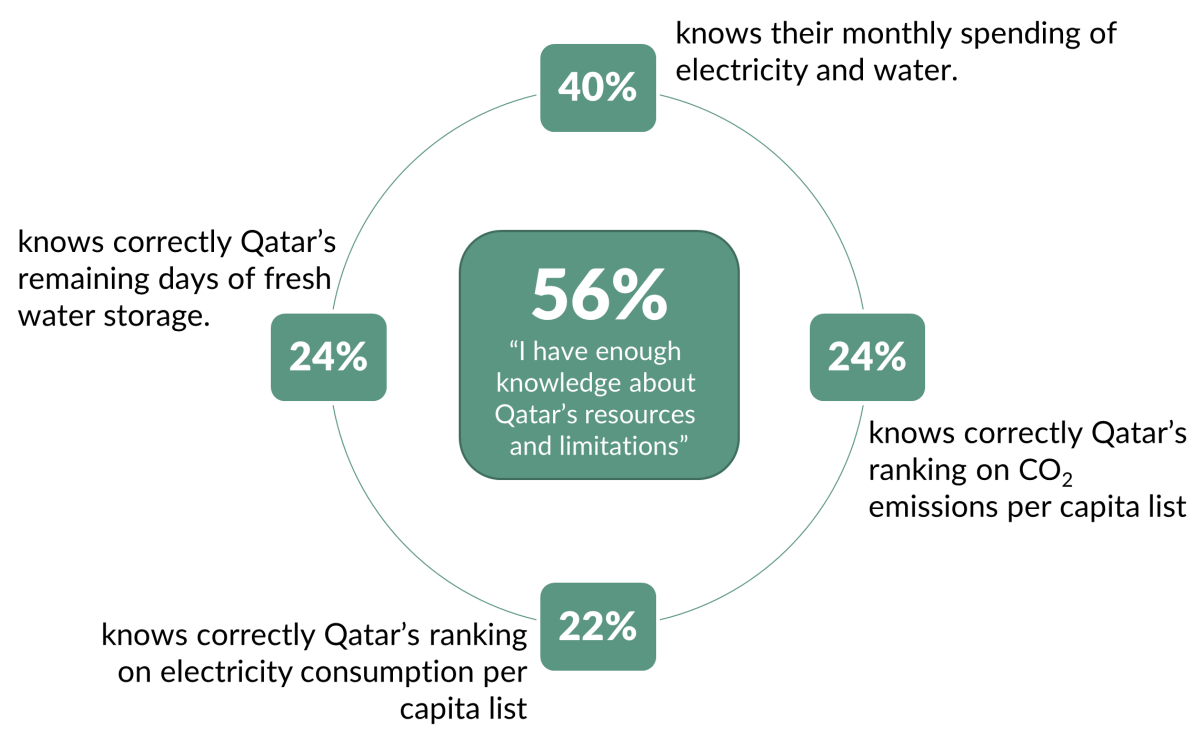

Figure 16. The level of knowledge Qatar population has on specific subjects about Qatar's resource limitations and their consumption levels.

\subsection{The Willingness Level of the Residents of Qatar}

In the last section of the survey, participants were asked how likely they agree to multiple statement questions on measuring their willingness, acceptance, and adaptation level about global, national and individual issues and possible DSM policies to be applicable in the country. Herein, only some of the important results are shared. The results will be provided as the accumulation of the percentages of 
'strongly agree' and 'agree' options. The willingness level of the participants about general issues is summarized in Figure 17 and Figure 18. The respondents overwhelmingly agree (89\%) to "the need or sacrifice in lifestyles to tackle the environmental problems" and "the need for more national programs and policies to conserve resources" to help them to consume less (70\%).

Regarding the specific policies and DSM measures as summarized in Figure 18, the respondents stated that they would use treated wastewater for non-important water-consumer tasks such as toilet flushing (72\%); they would like to install smart meter to be notified about the electricity consumption (73\%); they would like to learn the exact amount of electricity consumption at their homes $(73 \%)$. However, they agree relatively less to have a monthly limit on water consumption (54\%). Another interesting point is that the impact of the price of electricity (58\%), water (56\%), and gasoline (45\%) on their consumption behaviors would be relatively small according to the participant's statements. More detailed analysis will be provided in the next section and conclusion.

\subsection{Discussion}

According to the findings from this survey study summarized above, Qatar's population seem to have a relatively medium level of awareness to form their perception towards a sustainable society, environment, and development. However, they have serious lack of knowledge on specific subjects, which could help them to take necessary precautionary and less costly actions more aggressively and more consciously compared to unpredictable cost and effects of the after-the-fact disasters or circumstances. For instance, the survey tested the knowledge of the public about Qatar's resource utilization status and rankings in the world. Despite the fact that the society mostly (56\%) thinks they have an adequate awareness on "Qatar's limitations and consumption patterns (Q14)", only a tiny share of the public is actually aware and have enough knowledge of Qatar's exact resource limitations (24\% for fresh water storage) and high consumption rankings in the world (24\% for rating in $\mathrm{CO}_{2}$ emissions and $22 \%$ for the rating in electricity consumption) as shown in Figure 16 . For instance, most of the participants does not know about their monthly electricity (60\%) and water consumption (61\%), while only $27 \%$ of the participants pay their electricity bills. On the other hand, all of the participants who own a vehicle (72\%) knows their oil spending. These results indicate that the incentives and bill payment 
mechanism leave the society unaware of their consumption pattern. The first reason comes to the mind for this finding is a lack or limited access to information. Information campaigns through various sources would increase awareness and knowledge of the society. Another reason could be the fact that a significant number of expatriate residents in Qatar live there on a temporary basis without a commitment to long-term residency, cannot not own property and live in housing units rented by their employees. These leave them without any interest or care about their resource consumption patterns and spending levels in addition to the local citizens who are entitled to free utility services for their first residencies. In parallel with this opinion, the participants indicated their enthusiasm to learn more about environmental issues (81\%), their wish to have more awareness campaigns and national programs $(75 \%)$ to be implemented, and they request for more laws and regulations for the protection of the environment (78\%). Another interesting point from the survey, the society has been considered as the second most responsible entity (44\%) for the protection of the environment after the Ministry of Environment (82\%) which illustrates the desire of people on the requirement of policies developed by the government itself. Lastly, in the last section of the survey (i.e., willingness) regardless of their nationality, age group or income group; participants seem to be very willing to take action for the country's scarce resources. On average, every four out of five participants indicated they would participate in the most of the DSM programs to encourage themselves reducing their overall consumption. 


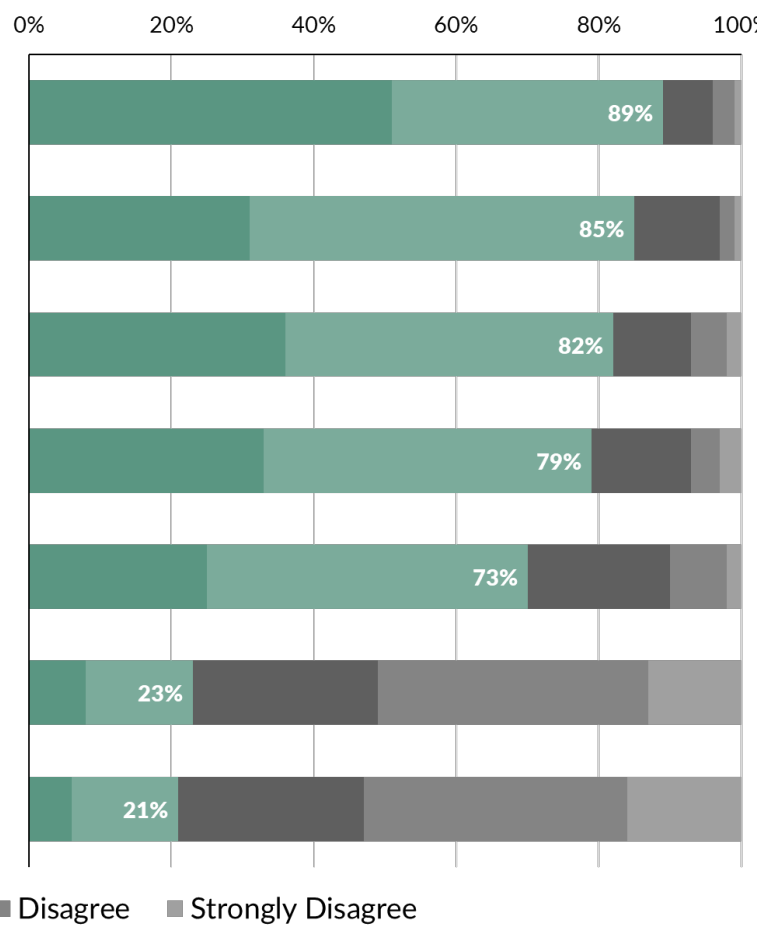

- Strongly Agree $\quad$ Agree $\quad$ Neutral $\square$ Disagree $\square$ Strongly Disagree

Figure 17. The attitude of the participants about general issues.

If I know that I use more electricity than my neighbors/national average; l'd try to use less.

To conserve water, l'd use treated wastewater for nonimportant tasks

l'd like to learn exact amount of electricity consumption in my home.

l'd like to install a smart meter to be notified about the electricity consumption.

I'd like to learn exact amount of water consumption in my home.

l'd like to install a smart meter to be notified about the water consumption.

I'd let someone manage my electricity consumption to conserve energy.

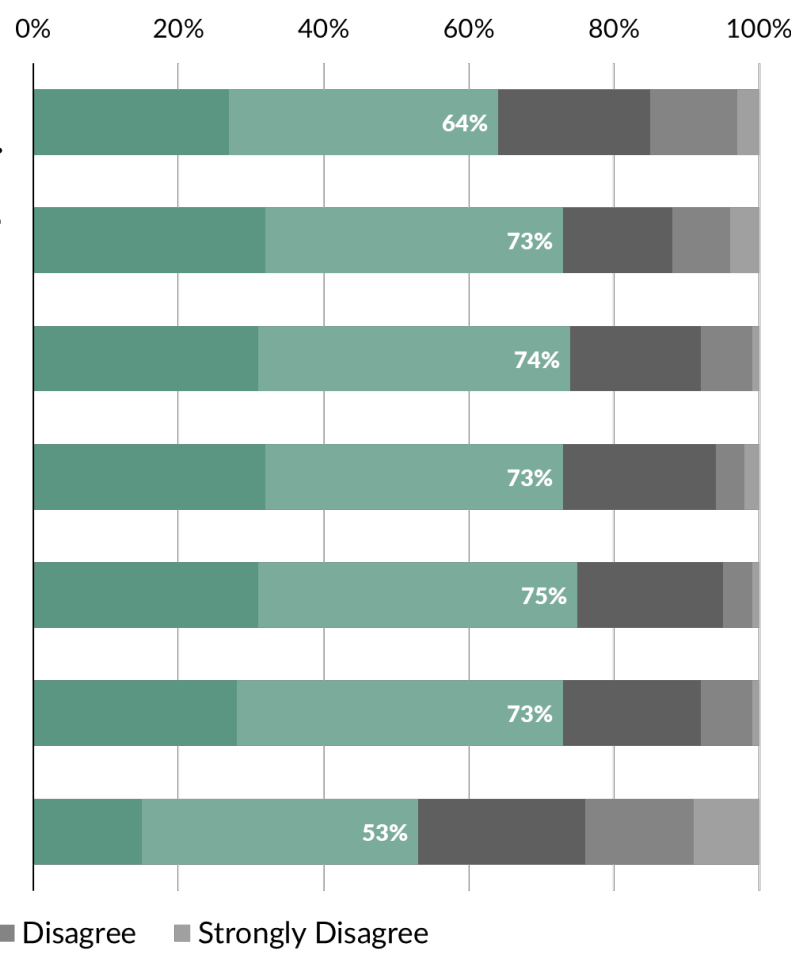

Figure 18. The willingness of the participants about specific policies and sectors. 
Moreover, some cross evaluations were made in order to obtain a better image on the perception and attitudes of Qatar population. Firstly, the answers of the demographic groups have been explored to exploit the correlations if there is any. Older participants (98\%) are more willing than younger ones (73\%) to restrain their lifestyles to protect the environment (Figure 19). As the income level increase, the willingness of using treated wastewater decreases (76\% - 65\%) (Figure 20). People with higher education levels are more likely be more willing for more laws and regulations to make ordinary citizens to protect the environment ( $85 \%$ - 50\%) (Figure 21).

Secondly, Qatari - Non-Qatari differentiation was analyzed. Although their percentage is only around $12 \%$, any policymaking process would mostly be shaped according to citizens' perception and beliefs. In awareness section, for instance, laws and regulations (73\%) is the most driving factor to protect the environment for Qataris while this rate is $49 \%$ for Non-Qataris. 62\% of the Qataris keep the temperature of the AC below $21^{\circ} \mathrm{C}$ while this rate is $35 \%$ for Non-Qataris. The transport mode inside the country for all Qataris is private car (100\%). Qataris use taxi (54\%) and private car (51\%) as their first two options when they are abroad, while Non-Qataris use public transportation (52\%). Qataris indicates social reasons is their primary reason (46\%) for not using public transport, while this reason comes 6 th amongst Non-Qataris with 22\%. Similarly, there are significant differences between Qataris and NonQataris in the willingness section, too. The prominent findings for willingness sections are reviewed in Figure 22. As deduced from the graph, the Qataris are unlikely to agree to the statements starting with "if I pay more ...". This indicates that price changes would not be a reasonable policy to nudge Qataris. However, the most significant difference between Qataris and Non-Qataris is about using treated wastewater. Only $50 \%$ of the Qataris agree to use treated wastewater while this rate is as high as $77 \%$ for Non-Qataris.

Lastly, a correlation between the awareness level and the willingness level has been researched in order to reveal if there is any relationship. For example, among the participants who think water scarcity is the most important environmental issue for Qatar, the willingness of using treated wastewater for unimportant tasks is significantly higher than others (93\% - 72\%). Furthermore, none of the participants 
who think society is the most responsible entity to protect environment keep their AC's temperature below $21{ }^{\circ} \mathrm{C}$, which means people take the initiative according to their beliefs. Lastly, the participants who think the resource depletion is the most important environmental issue for Qatar are more willing to restrain their consumerist lifestyles than others $(98 \%-85 \%)$.

As a result, Qatar has a unique duo in terms of awareness and willingness: low awareness and high willingness. This proves that the society is ready to take positive actions or to be nudged for a sustainable living and environmental protection if their awareness and knowledge can be increased through both information campaigns and carefully designed DSM policies, laws and regulations.

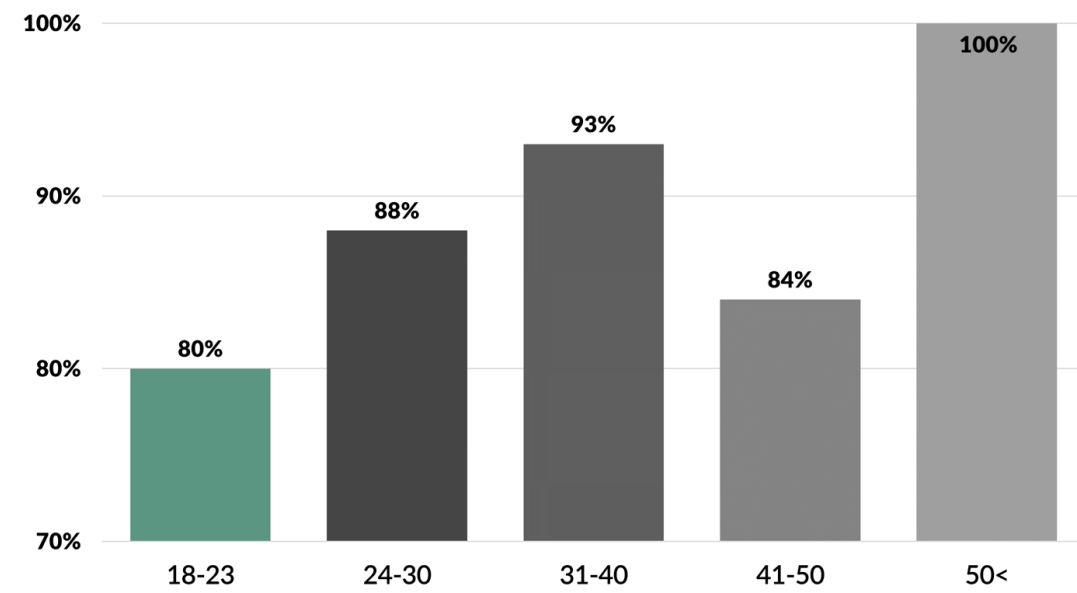

Figure 19. The correlation between age groups and the likeliness to restrain their lifestyles to protect the environment.

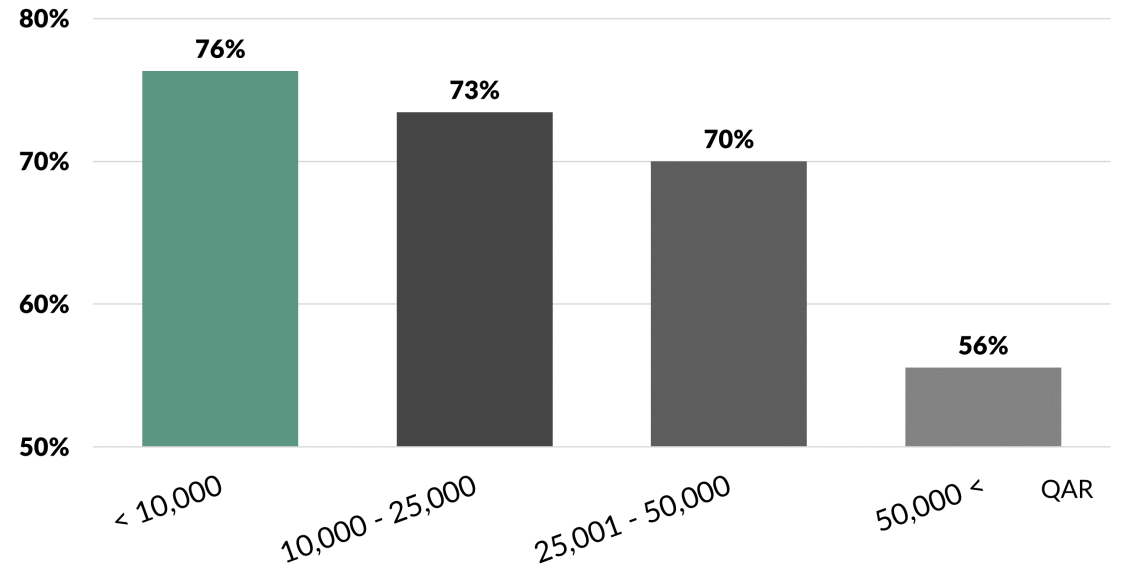

Figure 20. The correlation of income level and the likeliness to use treated wastewater. 


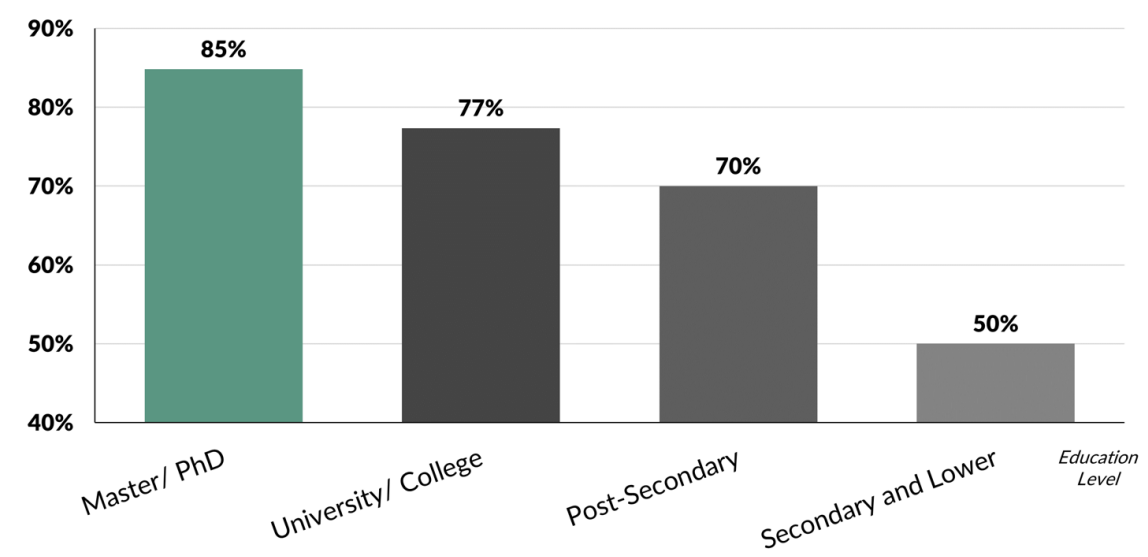

Figure 21. The correlation of education level and the likeliness to request for more laws \& regulations to make ordinary citizens to protect the environment.

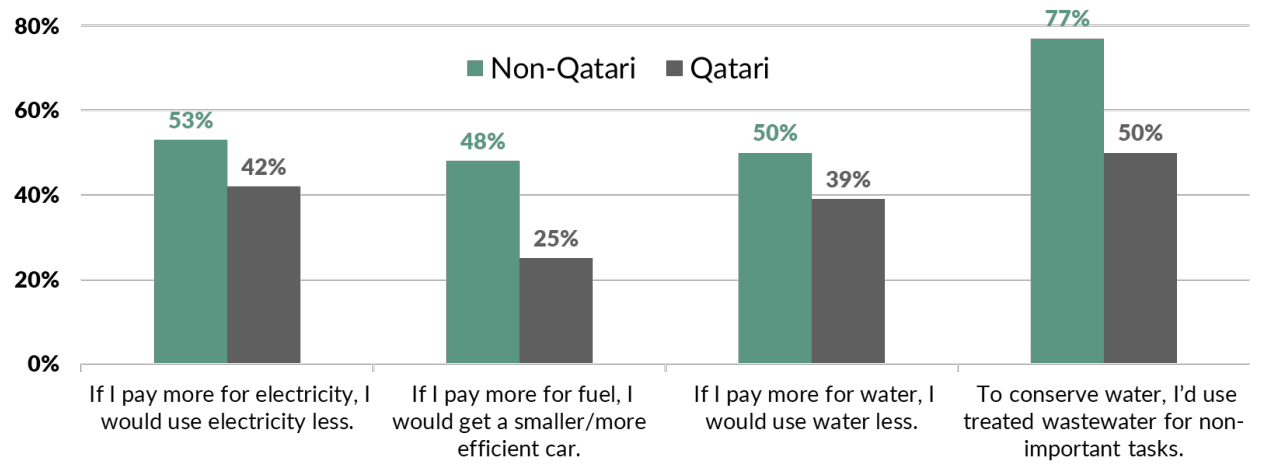

Figure 22. The difference willingness level between Qataris and Non-Qataris about specific subjects.

\section{Conclusion and Recommendations}

We have presented a framework and a survey study to devise and promote DSM applications in resource-rich countries. DSM is a part of cleaner production concept that aims to prevent wastage of resource generation, while increasing efficiencies in electricity, water, and transportation sectors. In the rest of the paper, we discuss our findings and present recommendations based on our findings.

\section{Framework and Survey Inferences}


From the economic perspective, resource-rich countries, Qatar in this case, have numerous advantages and disadvantages along the way of implementing DSM policies as well as unique benefits and challenges from their unique specifications. Economies of resource-rich countries is generally witnessed serious growth rates specifically after the energy becomes one of the most important aspects in daily life much more than before. As touched on in the framework, the common chronic economic issues of resource-rich countries are mostly derived on being depended on exports revenues of one good or resource. It was no different for Qatar whose economy draws its strength mostly from only one economic activity: exporting fossil fuels, mainly natural gas. Along with these chronic issues, some particular incidents such as the fluctuated fossil fuel prices, the common political tensions in the region, and more importantly, the ever-increasing demand driven by the economic boost may worsen the conditions and leave the country vulnerable against the genuine threats for economic stability.

Moreover, the solutions employed to eliminate those possible threats, are mostly supply-oriented such as highly subsidized tariffs on utilities, the national focus on boosting supply, and the trend of allocating a vast investment budget for the massive projects. Herein, DSM policies might offer cost-efficient alternative to current policies by modifying the people' consumption patterns. If the current policies stands as they are right now, the pressure over supply-side would grow, which would affect the stability of the economy. Even worse, after some time, the society may not even react to demand-controlling policies as expected because they are accustomed to their daily life too much. This problem is actually observed in the survey results of this study; People tend to give less importance to the policies involving price-changes which are among the most common DSM. Thus, Qatar's economy seriously needs some controlling measures on demand mechanisms, and herein, DSM has a lot to offer.

From the environment perspective; pollution of all kinds, global warming, land degradation, and stress level were considered as the environmental dimensions in the constructed framework. Since the resource-rich countries are increasing their total energy consumption by utilizing their natural resources which is among the leading reasons for environmental damaging, it is normal to see those countries among ones experiencing many problems based on pollution. The situation gets worse when it comes to middle-east due to other unique circumstances such as desert dust, construction-oriented economic activity and extreme temperatures. For Qatar, in national scale, firstly, the country is suffering from 
pollution issues, especially air pollution. During the last decade, Qatar's vehicle fleet has grown rapidly with a rate of $115 \%$; hence, it is not a surprise that the residents consider the traffic congestion in Doha as the second most critical urban issue for Qatar [Figure 15]. The respondents also point out air pollution as the most serious environmental issue for Qatar [Figure 15]. According to the survey results, from the promising perspective, people considers rail way is the best way to transport (62\%) by far [Figure 14], but, on the other hand, they still value private car most as the primary transport mode in the country (82\%), which contributes air pollution as well as $\mathrm{CO}_{2}$ emission. Therefore, we can conclude that, with the proper guidance policies and investments, people can easily adapt to more sustainable way to transport. Lastly, survey results reveal the harm of land degradation as the most serios urban issue in Qatar for the respondents is cost of living with $72 \%$ mainly driven by housing rents [Figure 15].

Along with air pollution, Qatar remained at the top of the $\mathrm{CO}_{2}$ emissions per capita list with 41 tons for 47 years since 1960 (Global Carbon Atlas, 2018; The World Bank, 2018). For comparison, by 2016, similar countries such as that Kuwait is $4^{\text {th }}$ with 26 tons, UAE is $5^{\text {th }}$ with 26 tons, Saudi Arabia is $9^{\text {th }}$ with 20 tons and Oman is $16^{\text {th }}$ with 15 tons (Global Carbon Atlas, 2018). However, the society is totally unaware of this infamous rank with $24 \%$ as it can be seen from the survey results [Figure 16]. Moreover, Qatar's top rank in the electricity and water consumption list is also unknown to the most of the population which makes difficult to take action about the issues and Qatar's global image. For the solution, on the contrary of the common belief, investments on supply such as investing road infrastructure or energy systems would not solve the problem instead worsen it by encouraging people to drive more. As a result, the need for policies in reducing such demand emerges. Supply-side investments such as building rail systems or expanding the existing public transportation network comprise only one part of solution. For permanent and sustainable solutions, modifying people usage behaviors with policies for increasing awareness of the users and encouraging them to use public transportation more is required for the sustainable development in the country. On this manner, the attitudes of Qatar society give hope for implementing such policies. According to the survey study we conducted, $90 \%$ of the society have heard global warming before and $89 \%$ of the society is ready to take action to overcome environmental problems [Figure 14, Figure 17]. Besides, global warming ranks $2^{\text {nd }}$ in terms of the most important environmental issue for Qatar [Figure 15]. For instance, car-pooling 
would be a good TDM policy option for Doha due to the city's relatively low population, good wealth level, wide area of land usage and extreme weather conditions.

From the social perspective; public awareness, public acceptance, the complexity of the systems, country resilience and public health were considered as the social dimensions of the constructed framework. Those characteristics and the initiatives help the society to have a reasonable level of consciousness and understanding level about the limitations, opportunities of the country, region and the earth. Majority of the respondents of the survey have stated that they have heard prominent environmental terms such as global warming and sustainability. Furthermore, they are aware of that climate change and air pollution are human-generated issues of the world in the survey. However, as mentioned before in the survey discussion section, the population has still serious lack of knowledge about a few certain issues. The society would be educated during the implementation of the policies. Regarding public acceptance in Qatar, with the ongoing urbanization and modernization in the country, the population has accustomed to witness radical changes, which would help the society adapt quickly and not resist to possible prospective DSM policies once they are communicated and campaigned in a reasonable way. Besides, a survey study has already revealed the society's positive point of view towards specific DSM policies existed across the world. For example, the respondents are ready to use treated wastewater as in $\operatorname{WDM}(73 \%)$, to make sacrifices in their daily lives $(89 \%)$, to expand their knowledge on environmental subjects by attending to awareness programs $(82 \%)$ and even to let someone control their consumption a bit as in direct load control program (53\%) [Figure 17, Figure 18]. Plus, the society account itself as the $2^{\text {nd }}$ responsible entity for solving the environmental problems with $43 \%$ [Figure 15 ].

From the technical perspective, technical efficiency, equipment and infrastructure, system reliability, and renewable energy integration were considered as the technical dimensions in the constructed framework. If not all, some of the DSM programs require technological advancements to a certain level. Herein, in terms of implementing DSM policies in the resource-rich countries, Qatar has utmost advantage in one sense due to its modern and new electrical grids, water distribution networks and road transport systems and its emphasis for efficiency; in other sense, Qatar is in need of those policies due to its renewable energy investments for energy and its increased need for high reliability in systems. The survey has also exhibited promising results such as that only $6 \%$ of the respondents do not want install 
smart meter in their home, only $8 \%$ do not want to be notified about electricity/water consumption, all of which requires device and equipment. Moreover, because of the growing population and consumption, the systems' reliability can sometimes be interrupted. At this point, systems could be modified according to the actual consumption with the help of DSM policies; hence the possible shortages can be prevented since the demand does not fluctuate as it used to be.

Lastly, the difference between Qataris and non-Qataris should be taken into consideration thoroughly before implementing any policy. For instance, from the survey results and the studies in literature, Qatari people are less responsive to price-based policies than non-Qataris while non-Qataris give less value to laws and regulations than Qataris. Therefore, different contradicted policies might be implemented in the same time to attract both part of the society.

As a summary, in the study, we aimed to demonstrate the potential opportunities and possible needs of resource-rich countries, by taking Qatar as a reference, by constructing a DSM Framework tailored for Qatar's unique dynamics. Moreover, a survey study was conducted to have a better understanding of the characteristics, norms and culture of the Qatar population which is crucial for the success of DSM policies. Hence, we have reached the conclusion that DSM is capable of offering a wide range of policies to enhance Qatar's current economic, environmental, technical, and social situation. In one sense, the country's unique dynamics allow the policies successfully to be employed such as having a society willing to participate in the DSM programs or modern and new infrastructure; in other sense, the country is in a position in which DSM programs could easily and effectively enhance the situation of the sector they implemented in such as renewable energy integration and global image. Qatar's circumstances and characteristics in terms of economy, environment, society and technology are ready and sufficient to have DSM programs in the country. It would not only help the supply side but also educate the society, help establishing a balanced economy, enhance the environment and wipe out environmental issues. In a country with almost no DSM application, almost any program could contribute to the outcomes. Some specific programs are touched upon below.

\section{Policy Recommendations}


In the light of the findings and observations deduced from the framework and the survey results, there are some policies that could be easily implemented. The chief policy recommendations may involve a wide range of demand management measures in, but not limited to, electricity, water, and transportation sectors including:

- More informative bill design and content: The first act to make people change their consumption behaviors is to inform them about their consumption levels (Lehner et al., 2016). As seen in the survey, people are willing to know their consumption as well as restraining their life-style in sake of environment, but they do not know certain and basic facts about country consumption figures. Thus, providing water and electricity bills to inform people is a must. They might be colored to increase attention or contain more detailed and informative interpretations such as the national/local average consumptions.

- Tariffs for Sustainability: The negative impacts of incentives are mentioned several times in the study; so, adjusting electricity, water, and oil tariffs step-by-step to reflect near-real-time cost of the provided service is required to achieve a successful deployment of potential DSM programs. However, for the most appropriate DSM program, price-based programs such as TOU should be avoided because the hourly change in electricity consumption is not a serious issue for Qatar. Besides, as seen in the survey results, the policies involved price changes does not affect respondents' decision as in other policies specifically among Qataris [Figure 22]. This is further supported by our previous work presented in (Bayram and Koc, 2017). Electricity tariffs in the neighboring country, the Kingdom of Bahrain, were doubled in March 2016. Using actual electricity consumption data for summer peak months, we showed that there is no change in peak electricity demand. This is because residents do not prefer to sacrifice the cooling comfort for financial savings. Instead, the programs aiming load conservation such as incentive based programs might be preferred. In parallel to our recommendation, in 2011, Eissa found that IBPs are much more effective than PBPs in Saudi Arabia which has similar characteristics as Qatar. For example, in short-term, demand bidding program would be a good choice for residential customers since it integrates the customer into electricity markets; hence it not only reduces the 
consumption but also increase customer awareness. For industrial customers, capacity market programs would be a good fit with their incentives upfront and penalties at the end; so that the creates behavioral bias on customers, loss aversion (Leidos, 2014).

- Promotion of smart meters in water and electricity: In line with the UN sustainability program, the electric and water utility company (Kahramaa) has been currently installing smart meters to the residents; however, their capabilities have been limited automated readings only. More advanced capabilities such as real-time consumption visualization would be very useful for various potential DSM programs and policies. With this improvement, additional programs can be introduced in the long term such as direct load program which has the fastest load reduction.

- Use of smart-thermostats: Air conditioning (AC) load represents the highest portion of domestic consumption. To promote sustainable energy usage, the government can mandate or promote the use of smart thermostats to remotely control AC units, particularly during summer when a sizable portion of the population is out of the country. In our previous work (Bayram and Koc, 2017), we estimated that nearly $4 \%$ of the peak consumption can be reduced by remotely cycling AC units one hour a day for residents who are out of the country. Moreover, (Bayram, 2019b) presents an electricity monitoring study for three typically villas in Qatar and shows that depending on set temperature and dwelling size nearly $100-300 \mathrm{kWh} /$ day of energy is used to for cooling when residents were not present during the first week of June 2019.

- Use of smart water heaters: Similar to AC units, water heaters represent a sizable portion of domestic consumption. Set temperatures are usually set at higher point which leads to wastage of energy and water even in summer months. Measurement study (see (Bayram, 2019b)) conducted at three typical villas in Qatar presents that nearly $50-60 \mathrm{kWh} /$ day of energy is consumed during the first week of June 2019 when residents are away for holiday. It is important to note that residents are not aware of their consumption and since electricity bills are subsidized they do not take any action. In line with the nation's sustainability goals, the use of remotely programmable thermostats can lead to significant savings without affecting end-user's comfort.

- Encouraging car-sharing applications: As the majority of Qatar population reside in Doha which is a relatively small city, reaching a vehicle easily in a very short period of time would encourage 
citizens to depend on those applications rather than their private car. In addition, most of the population (82\%) still accounts private car as the primary mode of transport, which is very high to change in short-term. This would also contribute reducing the number of cars in the roads and parking areas.

- $\quad$ Promoting electric vehicle usage: The government of Qatar is aiming to replace $10 \%$ of all vehicles with electric vehicles (EVs) (Bayram, 2019a). EVs are typically three to four times more efficient than combustion engine vehicles. Moreover, EVs are charged by power grid which produces electricity by natural gas (in Qatar). Since, pure EVs do not have tailpipes, they significantly improve local air quality (Soret et al., 2014). However, to promote EVs, government should provide incentives and develop a charging network that has the coverage and capacity to meet EV demand. In Qatar, the transportation sector is a major contributor to $\mathrm{NO}_{2}$ and particulate matter (PM) concentration which significantly degrades air quality. Electric vehicles offer clear benefits for urban air quality due to zero tailpipe emissions at road level. This is particularly important for Qatar as the vast majority of the population resides in urban city centers.

- Sustainable transport pricing: Most of the companies based in Qatar and the GCC region provide transportation allowance to purchase and use private vehicles. As Qatar Rail becomes fully operational, the governments and companies can revise benefit schemes to promote sustainable transportation. Moreover, deployment of park and ride facilities can provide more convenience to residents who are not walking-distance away from the metro stations. Such facilities can also be used as charging stations for electric vehicle owners who could enjoy green transportation. In addition, creating low emission zones in city centers would promote cleaner transportation options and improve air quality.

- Awareness programs about the policy on treated wastewater: According to the survey results, even though major part of the population (73\%) seem willing to use treated wastewater, locals mostly prefer not to use wastewater (50\%) specifically due to the health concerns (Saeed, 2018). Awareness programs might be helpful to express the true characteristics of treated wastewater for the locals. 
- More awareness sessions for the sponsors: As one of the unique characteristics of Qatar population, since the bills of almost all blue-collar workers and the majority of white-collar workers are paid by their sponsors, their awareness on consumption should be enhanced with such programs. In those sessions, potential annual saving can be calculated and provided to the sponsors to encourage them to enter the system. For instance, direct load program -an incentivebased program- can be emerged to reduce overall electricity demand in the worker houses while the appliances are not used.

- Technological improvements: Even though DSM mostly interests in modifying people consumption behaviors, improvements on particular equipment and infrastructure in any sector would increase the effects and success rate of the DSM policies. More sophisticated electrical grids, efficient ACs, advanced water distribution systems that prevent leakages, air-conditioned bus stops and wide rail systems to encourage people to increase use of public transportations can be given as examples to technological advancement.

\section{Limitations of the Study}

There are of course some limitations of the study. First of all, as the study was shaped as a review of DSM applications and the framework tailored to Qatar's needs, it does not include calculations of the possible effects of an actual DSM application. Secondly, the sectors within the study were limited with electricity, water, and transportation because including all the sectors requires much more efforts and time. Besides, demand controlling policies on other sectors have recently been implemented across the world; so, the number of studies and existing policies are limited. Last of all, for the survey study, the blue-collar workers, which are actually the significant part of the population, could not be represented thoroughly in the study as well as even in some statistics published by governmental entities due to their remote living areas and language barriers. It is noteworthy that the presented work is an initial step towards designing appropriate demand-side management programs. More accurate policy recommendations can be made by conducting a measurement study at various households. We have initiated a partnership with the local utility company and deployed more than 600 smart meters at Qatari households. We aim to expand our findings in this paper with data from measurement studies. 
It is further important to note that that DSM policies are specific to regions with similar characteristics. In this paper, we claim that DSM framework developed in Qatar can be applied (or provide good insights) in developing carbon-rich countries, e.g., neighboring countries in the Gulf region (Saudi Arabia, United Arab Emirates, Oman, Bahrain, and Kuwait). These countries have similar culture, soci-economic structure, consumption habits and climate conditions. For instance, most construction, service, car, and appliance (home, AC, etc.) companies are based in one GCC city and provide similar service and products to other GCC members. Also, GCC countries collectively represent 55 million in population, $640 \mathrm{TWh}$ annual electricity usage, and 5.7 billion cubic meter annual desalinated water usage (GCC Statistical Center, 2018). The region has an untapped DSM potential and the developed framework and survey results would potentially be beneficial for a large-scale implementation.

\section{Recommendations for Future Works}

As mentioned in the limitations of the research, in the future studies, researchers might deeply explore various kind of assessments (economic, environmental, etc.) of the certain DSM applications (direct load, car-sharing, etc.) in certain sector (electricity, water, transport, etc.) in Qatar; for instance; "Economic Assessment of Travel Demand Management Measures in Qatar". Moreover, instead of qualitative interpretation as demonstrated in this research, a quantitative interpretation of a particular program or policy might provide valuable insights for the future of possible policies. For another recommendation, comparing the benefits and privileges of some DSM applications in particular sector (e.g., comparison of CPP and TOU in electricity sector) regarding Qatar's limitations and opportunities would highly get help from this study and be an example for the future studies. In addition, in a broader study, similar frameworks could be constructed around other sectors such as food, waste, which are excluded from this framework due to the time limitations. Lastly, as similar to the survey study conducted in the study could be repeated with higher samples and confidence intervals in order to get a better image of society towards demand-oriented programs, applications, and policies.

\section{Acknowledgments}


Authors would like to acknowledge and extend thanks for that this research was conducted at Hamad bin Khalifa University with scholarship support from Qatar Foundation. The author would also like to thank I Batur for his valuable comments and feedback.

\section{References}

Abdulla, G., 2015. The deployment of advanced metering infrastructure, in: 2015 First Workshop on Smart Grid and Renewable Energy (SGRE). IEEE, pp. 1-3. https://doi.org/10.1109/SGRE.2015.7208738

Alasseri, R., Tripathi, A., Joji Rao, T., Sreekanth, K.J., 2017. A review on implementation strategies for demand side management (DSM) in Kuwait through incentive-based demand response programs. Renew. Sustain. Energy Rev. 77, 617-635. https://doi.org/10.1016/j.rser.2017.04.023

Albadi, M.H., El-Saadany, E.F., 2007. Demand response in electricity markets: An overview. 2007 IEEE Power Eng. Soc. Gen. Meet. PES 1-5. https://doi.org/10.1109/PES.2007.385728

Alpen Capital, 2016. GCC Healthcare Industry Report 1-93.

Alva Group, 2015. What is the Reputation Damage of VW's Emissions Admission?

Andersen, F.M., Jensen, S.G., Larsen, H. V, Meibom, P., Ravn, H., Skytte, K., Togeby, M., 2006. Analyses of Demand Response in Denmark. https://doi.org/10.1016/j.apenergy.2011.02.039

Annala, S., Lukkarinen, J., Primmer, E., Honkapuro, S., Ollikka, K., Sunila, K., Ahonen, T., 2018. Regulation as an enabler of demand response in electricity markets and power systems. J. Clean. Prod. 195, 1139-1148. https://doi.org/10.1016/J.JCLEPRO.2018.05.276

Bajželj, B., Richards, K.S., Allwood, J.M., Smith, P., Dennis, J.S., Curmi, E., Gilligan, C. a., Lee-gammage, W.S., Baj, B., Richards, K.S., Allwood, J.M., Smith, P., Dennis, J.S., Curmi, E., Gilligan, C. a., 2014. Importance of food-demand management for climate mitigation. Nat. Clim. Chang. 4, 924-929. https://doi.org/10.1038/nclimate2353

Barker, D.A., Barker, L.L., Emmert, P., 1989. Survey research 168-196.

Baumgärtner, N., Delorme, R., Hennen, M., Bardow, A., 2019. Design of low-carbon utility systems: Exploiting time-dependent grid emissions for climate-friendly demand-side management. Appl. Energy 247, 755-765. https://doi.org/10.1016/J.APENERGY.2019.04.029

Bayram, I.S., 2019a. A Stochastic Simulation Model to Assess the Impacts of Electric Vehicle Charging on Power Generation: A Case Study for Qatar, in: IEEE Transportation Electrification Conference and Expo. 
Bayram, I.S., 2019b. Non-intrusive Electricity Sub-metering in Selected Households in Qatar, in: IEEE 2019 The Fourth International Conference on UK-China Emerging Technologies, Glasgow, UK (Accepted).

Bayram, I.S., 2018. Energy Storage Sizing and Photovoltaic Self-Consumption in Selected Households in Qatar. IEEE 8th International Conference on Power and Energy Systems, Colombo, Sri Lanka.

Bayram, I.S., Koc, M., 2017. Demand side management for peak reduction and PV integration in Qatar, in: 2017 IEEE 14th International Conference on Networking, Sensing and Control (ICNSC). IEEE, pp. 251-256. https://doi.org/10.1109/ICNSC.2017.8000100

Bayram, I.S., Mohsenian-Rad, H., 2016. An overview of smart grids in the gec region, in: Smart City 360. Springer, pp. 301-313.

Bayram, I.S., Saffouri, F., Koc, M., 2018. Generation, analysis, and applications of high resolution electricity load profiles in Qatar. J. Clean. Prod. 183, 527-543. https://doi.org/10.1016/J.JCLEPRO.2018.02.084

Bayram, I.S., Ustun, T.S., 2017. A survey on behind the meter energy management systems in smart grid. Renew. Sustain. Energy Rev. 72, 1208-1232. https://doi.org/10.1016/J.RSER.2016.10.034

Bayram, I.S., V., C.O., Bigler, J., Fosse, J., Kayal, M., 2019. Demonstration of a Smart Villa Energy Monitoring Platform in Qatar, in: The Fourth International Conference on UK-China Emerging Technologies. Glasgow, UK.

Benes, J., Chauvet, M., Kamenik, O., Kumhof, M., Laxton, D., Mursula, S., Selody, J., 2015. The future of oil: Geology versus technology. Int. J. Forecast. 31, 207-221. https://doi.org/10.1016/j.ijforecast.2014.03.012

"Biggest Natural Gas Reserves,” 2013. The world's biggest natural gas reserves - Hydrocarbons Technology [WWW Document]. URL http://www.hydrocarbons-technology.com/features/feature-the-worlds-biggestnatural-gas-reserves/ (accessed 5.31.17).

Bolarinwa, O.A., 2015. Principles and methods of validity and reliability testing of questionnaires used in social and health science researches. Niger. Postgrad. Med. J. 22, 195-201. https://doi.org/10.4103/11171936.173959

Braithwaite, S., Cave, D., International Assocoation for Energy Economics, 1994. Three Biases in Cost-Efficiency Tests of Utility Energy Efficiency. Energy J. 15, 95-120.

British Petroleum, 2018. BP World Energy Statistics 1964-2018 (All Data).

Butler, D., Memon, F.A., 2016. Water Demand Management - David Butler, Fayyaz Ali Memon. IWA Publishing.

Cairns, S., Sloman, L., Newson, C., Anable, J., Kirkbride, A., Goodwin, P., 2008. Smarter Choices: Assessing the Potential to Achieve Traffic Reduction Using 'Soft Measures.' Transp. Rev. 28, 593-618. 
https://doi.org/10.1080/01441640801892504

“Carrying Capacity," 2016. Carrying Capacity - World Population History [WWW Document]. URL http://worldpopulationhistory.org/carrying-capacity/ (accessed 3.16.18).

Castillo, A.B., Al-Maslamani, I., Obbard, J.P., 2016. Prevalence of microplastics in the marine waters of Qatar. Mar. Pollut. Bull. 111, 260-267. https://doi.org/10.1016/j.marpolbul.2016.06.108

CEIC Data, 2017. Qatar | Number of Registered Motor Vehicles | Economic Indicators [WWW Document]. URL https://www.ceicdata.com/en/qatar/number-of-registered-motor-vehicles/number-of-registered-motorvehicles (accessed 11.4.18).

Central Intelligence Agency, 2012. Electricity From Fossil Fuels - The World Factbook [WWW Document]. URL https://www.cia.gov/library/publications/the-world-factbook/rankorder/2237rank.html\#qa (accessed 5.31.17).

Chambers, M.J., Gregg, M.G., Ling, C.C., 1990. Time of use pricing and two-way communications technology, SEQEB moves towards home automation, in: Sixth International Conference on Metering Apparatus and Tariffs for Electricity Supply, Manchester, UK. Manchester, UK, pp. 21-25.

Cigre Working Group, 2011. Demand Side Integration, 2007 IEEE Lausanne Power Tech.

Cohen, L., Manion, L., Morrison, K., 2007. Research methods in education, 6th ed. Routledge.

Cominola, A., Giuliani, M., Piga, D., Castelletti, A., Rizzoli, A.E., 2015. Benefits and challenges of using smart meters for advancing residential water demand modeling and management: A review. Environ. Model. Softw. 72, 198-214. https://doi.org/10.1016/J.ENVSOFT.2015.07.012

Darwish, M.A., Abdulrahim, H.K., Mohieldeen, Y., 2015. Qatar and GCC water security. Desalin. Water Treat. 55, 2302-2325. https://doi.org/10.1080/19443994.2014.947782

Dorsey, B., 2005. Mass transit trends and the role of unlimited access in transportation demand management. J. Transp. Geogr. 13, 235-246. https://doi.org/10.1016/j.jtrangeo.2004.07.004

Dr. Edward Spang, 2009. A thirst for power: A global analysis of water consumption for energy production. Glob. Water Forum. https://doi.org/10.1073/pnas.0812619106

Dubai Supreme Council of Energy, 2015. Dubai Demand Side Management Strategy 2015 Annual Report "The future is efficient ". Dubai.

Dulleck, U., Kaufmann, S., 2000. On the effectiveness of DSM information programs on household electricity demand, University of Vienna.

Eissa, M.M., 2011. Demand side management program evaluation based on industrial and commercial field data. 
Energy Policy 39, 5961-5969. https://doi.org/10.1016/j.enpol.2011.06.057

El-Katiri, L., Fattouh, B., 2015. A Brief Political Economy of Energy Subsidies in the Middle East and North Africa. Oxford, United Kingdom. https://doi.org/10.26889/9781784670214

"Energy Subsidies," 2015. IMF Survey: Counting the Cost of Energy Subsidies [WWW Document]. URL https://www.imf.org/en/News/Articles/2015/09/28/04/53/sonew070215a (accessed 2.18.18).

Eto, J., 1996. The Past, Present, and Future of U.S. Utility Demand-Side Management Programs.

"First electric car," 2018. First electric car charging station opens in Qatar - The Peninsula Qatar [WWW Document]. URL https://thepeninsulaqatar.com/article/27/02/2018/First-electric-car-charging-stationopens-in-Qatar (accessed 7.3.19).

"Five Years After Deepwater Horizon," 2015. Five Years After Deepwater Horizon, Can BP Repair Its \begin{tabular}{l|llll} 
Reputation? & Sustainable & Brands & [WWW & Document
\end{tabular} http://www.sustainablebrands.com/news_and_views/marketing_comms/leon_kaye/five_years_after_deepw ater_horizon_can_bp_repair_its_reputa (accessed 3.13.18).

"framework," n.d. framework | meaning in the Cambridge English Dictionary [WWW Document]. URL https://dictionary.cambridge.org/dictionary/english/framework (accessed 8.18.19).

Freije, A.M., 2015. Heavy metal, trace element and petroleum hydrocarbon pollution in the Arabian Gulf: Review. J. Assoc. Arab Univ. Basic Appl. Sci. 17, 90-100. https://doi.org/10.1016/j.jaubas.2014.02.001

Friedrichs, J., Inderwildi, O.R., 2013. The carbon curse: Are fuel rich countries doomed to high CO2 intensities? Energy Policy 62, 1356-1365. https://doi.org/10.1016/J.ENPOL.2013.07.076

Galor, O., Moav, O., 2005. Natural Selection and the Evolution of Life Expectancy. Evolution (N. Y). 36. https://doi.org/10.2139/ssrn.563741

Gaouda, A., Abdel-Hafez, M., Alahmad, M., Shuaib, K., Aljuhaishi, N., Sharif, H., 2013. Conserving energy in UAE buildings: Demand side management and methods for experiencing energy, in: 2013 7th IEEE GCC Conference and Exhibition (GCC). IEEE, pp. 33-38. https://doi.org/10.1109/IEEEGCC.2013.6705744

GCC Statistical Center, 2018. GCC Outlook 2018.

Gellings, C.W., 1981. Demand-side load management. IEEE Spectr.

General Secretariat for Development Planning, 2009. Qatar National Vision 2030: Advancing Sustainable Development. Qatar's Second Human Development Report.

Gils, H.C., 2014. Assessment of the theoretical demand response potential in Europe. Energy 67, 1-18. https://doi.org/10.1016/j.energy.2014.02.019 
Global Carbon Atlas, 2018. CO2 Emissions Ranking by Year (tCO2/person) [WWW Document]. URL http://www.globalcarbonatlas.org/en/CO2-emissions (accessed 11.19.18).

“Green Car Initiative" , 2017. MoU signed to launch "Green Car Initiative” [WWW Document]. URL https://www.km.com.qa/MediaCenter/pages/NewsDetails.aspx?ItemID=224 (accessed 5.9.19).

Hayes, S., Baum, N., Herndon, G., 2013. Energy Efficiency : Is the United States Improving ? Am. Counc. Energy Effic. Econ.

Hertog, S., Luciani, G., 2009. Energy and Sustainability Policies in the GCC. Kuwait Program. Dev. Gov. Glob. Gulf States 44, 49.

Hirst, ERIC, John, R., Bronfman, B.E., Fitzpatrick, G., Hicks, E., Hirst, Eric, Marc, H., Keating, K., Michaels, H., Nadel, S., Peters, J., Reed, J., Saxonis, W., Schon, A., Daniel, V., 1992. Handbook of Evaluation of Utility DSM Programs.

Hopkins, K., 1966. On the probable age structure of the Roman population. Popul. Stud. (NY). 20, $245-264$. https://doi.org/10.1080/00324728.1966.10406097

Hu, Z., Moskovitz, D., Zhao, J., 2005. Demand-Side Management in China’s Restructured Power Industry How Regulation and Policy Can Deliver Demand-Side Changing Power System, The World Bank, ESMAP.

Institute of Health Metrics and Evaluation, 2013. GBD 2013: global burden of diseases, injures, and risk factors protocol. https://doi.org/10.1111/j.1444-2906.2008.01549.x

International Energy Agency, 2010. World Energy Outlook 2009. World Energy Outlook 23, 326-328. https://doi.org/10.1049/ep.1977.0180

IPART, 2001. Inquiry into the Role of Demand Management and Other Options in the Provision of Energy Services: Issues Paper.

Janahi, I.A., Bener, A., Bush, A., 2006. Prevalence of Asthma among Qatari Schoolchildren: International Study of Asthma and Allergies in Childhood, Qatar. Pediatr. Pulmonol. 41, 80-86. https://doi.org/10.1002/ppul.20331

Jasim, S.Y., Saththasivam, J., Loganathan, K., Ogunbiyi, O.O., Sarp, S., 2016. Reuse of Treated Sewage Effluent (TSE) in Qatar. J. Water Process Eng. 11, 174-182. https://doi.org/10.1016/J.JWPE.2016.05.003

Jazayeri, P., Schellenberg, A., Rosehart, W.D., Doudna, J., Widergren, S., Lawrence, D., Mickey, J., Jones, S., 2005. A survey of load control programs for price and system stability. IEEE Trans. Power Syst. 20, 15041509. https://doi.org/10.1109/TPWRS.2005.852147

Jean-Baptiste Say, 1836. A Treatise on Political Economy (Traité d'économie politique). Grigg \& Elliot. 
Jiang, Y., Cai, W., Du, P., Pan, W., Wang, C., 2015. Virtual water in interprovincial trade with implications for China's water policy. J. Clean. Prod. 87, 655-665. https://doi.org/10.1016/J.JCLEPRO.2014.10.074

Jraiw, K., 2015. Transport demand management - Impacts on congestion alleviation and road safety enhancement in urban areas. J. Local Glob. Heal. Sci. 2015, 83. https://doi.org/10.5339/jlghs.2015.itma.83

Kahramaa, 2016a. Annual Qatar Statistics Report 2016.

Kahramaa, 2016b. Kahramaa Achievements 2015.

Kahramaa, 2015. Qatar Statictics Report 2015.

Kahramaa, 2012. Conservation Plan for Tarsheed.

"Kahramaa announces," 2012. Kahramaa announces the launch of Tarsheed - Qatar is Booming [WWW Document]. URL http://www.qatarisbooming.com/article/kahramaa-announces-launch-tarsheed (accessed 4.12.18).

“Kahramaa hikes tariffs,” 2015. Kahramaa hikes water, electricity tariffs - GulfTimes [WWW Document]. URL http://www.gulf-times.com/story/458727/Kahramaa-hikes-water-electricity-tariffs (accessed 4.12.18).

“Kahramaa SMS service,” 2018. Kahramaa SMS service to inform utility usage rate - The Peninsula Qatar [WWW Document]. URL https://thepeninsulaqatar.com/article/02/01/2018/Kahramaa-SMS-service-to-informutility-usage-rate (accessed 4.12.18).

Khan, I., 2019. Energy-saving behaviour as a demand-side management strategy in the developing world: the case of Bangladesh. Int. J. Energy Environ. Eng. 1-18. https://doi.org/10.1007/s40095-019-0302-3

Khan, I., Jack, M.W., Stephenson, J., 2019. Identifying residential daily electricity-use profiles through timesegmented regression analysis. Energy https://doi.org/10.1016/J.ENBUILD.2019.04.026

Kiani, A., 2017. Coupling effects of demand-side improvements ensemble on energy performance to monetary implications for UAE economy. J. Clean. Prod. 167, 44-54. https://doi.org/10.1016/J.JCLEPRO.2017.08.133

“Large Scale Solar Power Plant,” 2018. Kahramaa to Request Bids for a Large Scale Solar Power Plant [WWW Document]. URL https://www.km.qa/MediaCenter/pages/NewsDetails.aspx?ItemID=281 (accessed 11.4.18).

Lau, E.T., Yang, Q., Stokes, L., Taylor, G.A., Forbes, A.B., Clarkson, P., Wright, P.S., Livina, V.N., 2015. Carbon savings in the UK demand side response programmes. Appl. Energy 159, 478-489. https://doi.org/10.1016/J.APENERGY.2015.08.123 
Lehner, M., Mont, O., Heiskanen, E., 2016. Nudging - A promising tool for sustainable consumption behaviour? J. Clean. Prod. 134, 166-177. https://doi.org/10.1016/J.JCLEPRO.2015.11.086

Leidos, 2014. Behavioral Economics Applied to Energy Demand Analysis.

Lu, R., Hong, S.H., Zhang, X., 2018. A Dynamic pricing demand response algorithm for smart grid: Reinforcement learning approach. Appl. Energy 220, 220-230. https://doi.org/10.1016/J.APENERGY.2018.03.072

Lu, X., Zhou, K., Zhang, X., Yang, S., 2018. A systematic review of supply and demand side optimal load scheduling in a smart grid environment. J. Clean. Prod. 203, 757-768. https://doi.org/10.1016/J.JCLEPRO.2018.08.301

Mah, D.N., Lam, V., Siu, A., Ye, H., Ogata, S., Wu, Y.-Y., 2018. Understanding undergraduate students' perceptions of dynamic pricing policies: An exploratory study of two pilot deliberative pollings (DPs) in Guangzhou, China and Kyoto, Japan. J. Clean. Prod. 202, 160-173. https://doi.org/10.1016/J.JCLEPRO.2018.07.255

Malik, A.S., 2007. Impact on power planning due to demand-side management (DSM) in commercial and government sectors with rebound effect-A case study of central grid of Oman. Energy 32, 2157-2166. https://doi.org/10.1016/j.energy.2007.05.004

Mara, D., 2013. Domestic Wastewater Treatment in Developing Countries. Routledge. https://doi.org/10.4324/9781849771023

Marwan, M., Kamel, F., 2010. User-controlled electrical energy consumption towards optimized usage of electricity infrastructure, in: Southern Region Engineering Conference, SREC 2010, Toowoomba, Australia. Toowoomba, Australia.

Max Roser based on World Bank and Bourguignon and Morrisson (2002), 2016. World population living in extreme poverty [WWW Document]. URL https://ourworldindata.org/grapher/share-world-population-inextreme-poverty-absolute?country=OWID_WRL (accessed 5.22.17).

Max Roser on the basis of the Gapminder, the W.B., 2016. Global child mortality [WWW Document]. URL https://ourworldindata.org/grapher/global-child-mortality-timeseries (accessed 5.22.17).

Melorose, J., Perroy, R., Careas, S., 2015. World population prospects. United Nations 1, 587-92. https://doi.org/10.1017/CBO9781107415324.004

Metz, H.C., 1994. Persian Gulf states: country studies.

Meyabadi, A.F., Deihimi, M.H., 2017. A review of demand-side management: Reconsidering theoretical framework. Renew. Sustain. Energy Rev. 80, 367-379. https://doi.org/10.1016/J.RSER.2017.05.207 
Ministry of Development Planning and Statistics, 2018. Qatar Monthly Statistics.

Ministry of Development Planning and Statistics, 2017. Qatar In Figures.

Ministry of Development Planning and Statistics, 2016. Population and Social Statistics.

Mishrif, A., Al Balushi, Y., 2018. Economic diversification in the Gulf Region : the private sector as an engine of growth. Palgrave Macmillan. https://doi.org/10.1007/978-981-10-5783-0

Mohammed, S.S., 2017a. Environmental Awareness, Attitudes and Actions: A Baseline Survey of the Citizens and Residents of Qatar. https://doi.org/10.6084/m9.figshare.5745390.v1

Mohammed, S.S., 2017b. Environmental Awareness, Attitudes and Actions: A Baseline Survey of the Citizens and Residents of Qatar. https://doi.org/10.6084/m9.figshare.5745390.v1

Mohammed, S.S., 2016. Qatar's National Emission Inventory. https://oi.org/10.6084/m9.figshare.4154238.v1

Murthy Balijepalli, V.S.K., Pradhan, V., Khaparde, S.A., Shereef, R.M., 2011. Review of demand response under smart grid paradigm, in: ISGT2011-India. IEEE, pp. 236-243. https://doi.org/10.1109/ISETIndia.2011.6145388

NASA, 2018. Climate Change: Vital Signs of the Planet: Effects [WWW Document]. URL https://climate.nasa.gov/effects/ (accessed 3.13.18).

Nicholls, L., Strengers, Y., 2015. Peak demand and the 'family peak' period in Australia: Understanding practice (in)flexibility in households with children. Energy Res. Soc. Sci. 9, 116-124. https://doi.org/10.1016/J.ERSS.2015.08.018

Nolan, S., O’Malley, M., 2015. Challenges and barriers to demand response deployment and evaluation. Appl. Energy 152, 1-10. https://doi.org/10.1016/J.APENERGY.2015.04.083

Observatory of Economic Complexity, 2017. Qatar (QAT) Exports, Imports, and Trade Partners [WWW Document]. URL https://atlas.media.mit.edu/en/profile/country/qat/ (accessed 2.4.18).

OECD, 2015. How's life? 2015: Measuring Well-being, How's Life? 2015: Measuring well-being. https://doi.org/10.1787/how_life-2015-en

OPEC, 2017. Qatar Facts and Figures 2017 [WWW Document]. URL https://www.opec.org/opec_web/en/about_us/168.htm (accessed 11.3.18).

Paulus, M., Borggrefe, F., 2011. The potential of demand-side management in energy-intensive industries for electricity markets in Germany. Appl. Energy 88, $432-441$. https://doi.org/10.1016/J.APENERGY.2010.03.017

“Percentage of Income on Electricity," 2015. Percentage of Household Income Spent on Electricity by State - 
Electric Choice [WWW Document]. URL https://www.electricchoice.com/blog/percentage-incomeelectricity/ (accessed 2.3.19).

Pérez Arriaga, I., Knittel et al, C., 2016. Utility of the Future. An MIT Energy Initiative response.

Pina, A., Silva, C., Ferrão, P., 2012. The impact of demand side management strategies in the penetration of renewable electricity. Energy 41, 128-137. https://doi.org/10.1016/j.energy.2011.06.013

Potter, J., Stuart, E., Cappers, P., 2018. Barriers and Opportunities to Broader Adoption of Integrated Demand Side Management at Electric Utilities: A Scoping Study. E-Scholarship Repository, Berkeley, CA (United States). https://doi.org/10.2172/1425437

“Power failure at Pearl,” 2016. Power failure at Pearl-Qatar making life harder for residents and businesses - Qatar Living [WWW Document]. URL http://www.qatarliving.com/forum/news/posts/power-failure-pearl-qatarcauses-chaos (accessed 2.19.18).

Powerwise, n.d. Smart Metering Trial - Powerwise [WWW Document]. URL http://www.powerwise.gov.ae/en/research/programmes-projects/time-of-day-trial.html (accessed 10.3.17).

“Qatar's 2017 budget,” 2016. Qatar's 2017 budget entails QR198.4bn expenditure - Gulf Times [WWW Document]. URL https://www.gulf-times.com/story/524828/Qatar-s-2017-budget-entails-QR198-4bnexpenditure (accessed 8.20.19).

"Qatar Crisis," 2017. Qatar crisis: What you need to know - BBC News [WWW Document]. URL https://www.bbc.com/news/world-middle-east-40173757 (accessed 11.4.18).

Qatar General Secretariat for Development Planning, 2011. Qatar National Development Strategy 2011 2016.

Qatar General Secretariat for Development Planning, 2008. Qatar National Vision 203039.

Qatar Planning and Statistics Authority, 2017. Environment Statistics Bulletin 2017.

“Qatar Rail to Open,” 2019. Qatar Rail to open more stations on Red Line soon - The Peninsula Qatar [WWW Document]. URL https://thepeninsulaqatar.com/article/29/05/2019/Qatar-Rail-to-open-more-stations-onRed-Line-soon (accessed 7.3.19).

"Qatar rents ranked third," 2015. Qatar rents ranked third most expensive in the world - ArabianBusiness [WWW Document]. Arab. Bus. URL http://www.arabianbusiness.com/qatar-rents-ranked-third-most-expensive-inworld-581459.html (accessed 3.16.18).

“Qatar to boost," 2017. Qatar to boost gas production by 30\% to 100 million tonnes a year - The Peninsula Qatar [WWW Document]. URL https://thepeninsulaqatar.com/article/04/07/2017/Qatar-to-boost-gas-productionby-30-to-100-million-tonnes-a-year (accessed 2.4.18). 
Qatarbiobank, 2017. Qatar Biobank Report 2016/2017.

QatarGas, 2016. Sustainability Report.

QMIC, 2017. Qatar Traffic Report (QTR) 2016 [WWW Document]. URL http://www.qmic.com/news/qmiclaunches-the-qatar-traffic-report-for-2016/ (accessed 2.19.18).

Risteska Stojkoska, B.L., Trivodaliev, K. V., 2017. A review of Internet of Things for smart home: Challenges and solutions. J. Clean. Prod. 140, 1454-1464. https://doi.org/10.1016/J.JCLEPRO.2016.10.006

Saeed, B.M., 2018. The Public Perception In The Reuse Of Treated Industrial Water And Bio-Sludge. Hamad bin Khalifa University.

Sáez-Martínez, F.J., Lefebvre, G., Hernández, J.J., Clark, J.H., 2016. Drivers of sustainable cleaner production and sustainable energy options. J. Clean. Prod. 138, 1-7. https://doi.org/10.1016/J.JCLEPRO.2016.08.094

Saffouri, F.I., 2017. Data-Driven DSM in Qatar's Electricity Sector. Hamad bin Khalifa University / Doha.

Salahuddin, M., Gow, J., 2014. Economic growth, energy consumption and CO2 emissions in Gulf Cooperation Council countries. Energy 73, 44-58. https://doi.org/10.1016/J.ENERGY.2014.05.054

Shuval, H., Dweik, H., 2007. Water Resources in the Middle East Israel-Palestinian Water Issues - From Conflict to Cooperation. Springer.

“Solar Energy to meet," 2016. Solar energy to meet 20\% of Qatar's energy demand by 2030 - GulfTimes [WWW Document]. URL http:/www.gulf-times.com/story/501761/Solar-energy-to-meet-20-of-Qatar-s-energydemand-b (accessed 2.18.18).

Soret, A., Guevara, M., Baldasano, J.M., 2014. The potential impacts of electric vehicles on air quality in the urban areas of Barcelona and Madrid (Spain). Atmos. Environ. 99, 51-63. https://doi.org/10.1016/J.ATMOSENV.2014.09.048

"supply and demand," n.d. supply and demand | meaning in the Cambridge English Dictionary [WWW Document]. URL https://dictionary.cambridge.org/dictionary/english/supply-and-demand (accessed 8.18.19).

The Atlantic, 2018. Leaving the Paris Agreement Would Be Indefensible.

The Brattle Group, 2007. Quantifying Demand Response Benefits in PJM. Brattle Group, Inc.

The Economist, 2017. Say's law: supply creates its own demand [WWW Document]. URL https://www.economist.com/news/economics-brief/21726050-third-brief-our-series-looks-reasoning-madejean-baptiste-say (accessed 10.8.17).

The Washington Post, 2018. As the U.S. leaves Paris climate accord, some see shifts in global leadership - The Washington Post. 
The World Bank, 2018. CO2 Emissions per capita by Country - World Development Indicators [WWW Document].

URL http://databank.worldbank.org/data/reports.aspx?source=2\&series=EN.ATM.CO2E.PC\&country=\# (accessed 5.31.17).

The World Bank, 2015. Qatar Population Growth [WWW Document]. URL http://data.worldbank.org/indicator/SP.POP.TOTL? contextual=default\&end=2015\&locations=QA\&start=1 960\&view=chart (accessed 5.31.17).

Torriti, J., 2017. Peak energy demand and demand side response. Routledge.

U.S. Department of Energy, 2006. Benefits of Demand Response in Electricity Markets and Recommendations for Achieving Them.

“Unexpected power outage,” 2016. Unexpected power outage hits Doha - Qatar Tribune [WWW Document]. URL http://qatar-tribune.com/news-details/id/21438 (accessed 2.19.18).

United Nations Sustainable Development, 2019. The Sustainable Development Agenda [WWW Document]. URL https://www.un.org/sustainabledevelopment/development-agenda/ (accessed 7.3.19).

US Department of Commerce, NOAA, E.S.R.L., 2017. ESRL Global Monitoring Division - Global Greenhouse Gas Reference Network.

Vázquez-Canteli, J.R., Nagy, Z., 2019. Reinforcement learning for demand response: A review of algorithms and modeling techniques. Appl. Energy 235, 1072-1089. https://doi.org/10.1016/J.APENERGY.2018.11.002

Vermeyen, P., 2008. Effect of distributed generation on fault detection and ripple control, Ph.D. Thesis. Katholieke Universiteit Leuven.

Wang, H., Fang, H., Yu, X., Liang, S., 2018. How real time pricing modifies Chinese households' electricity consumption. J. Clean. Prod. 178, 776-790. https://doi.org/10.1016/J.JCLEPRO.2017.12.251

Wang, J., Bloyd, C.N., Hu, Z., Tan, Z., 2010. Demand response in China. Energy 35, 1592-1597. https://doi.org/10.1016/j.energy.2009.06.020

Wang, Y., Lin, H., Liu, Y., Sun, Q., Wennersten, R., 2018. Management of household electricity consumption under price-based demand response scheme. J. Clean. Prod. 204, 926-938. https://doi.org/10.1016/J.JCLEPRO.2018.09.019

Warren, P., 2014. A review of demand-side management policy in the UK. Renew. Sustain. Energy Rev. 29, 941951. https://doi.org/10.1016/j.rser.2013.09.009

Waterwise, n.d. In-home Water Use Audit Project (IHWA) [WWW Document]. URL 
http://www.waterwise.gov.ae/en/research/research-studies/in-home-water-use-audit-project.html (accessed 10.3.17a).

Waterwise, n.d. Residential End Use of Water (REUW) Project [WWW Document]. URL http://www.waterwise.gov.ae/en/research/research-studies/residential-end-use-of-water.html (accessed 10.3.17b).

Waterwise, n.d. Water Consumption and Return-to-Sewer (RTS) Study [WWW Document]. URL http://www.waterwise.gov.ae/en/research/research-studies/water-consumption-and-return-to-sewerstudy.html (accessed 10.3.17c).

WHO, 2016. WHO | Life expectancy. WHO.

World Bank, 2018a. Population by Year [WWW Document]. URL https://data.worldbank.org/indicator/sp.pop.totl (accessed 9.30.18).

World Bank, 2018b. Qatar Population by Year [WWW Document]. URL https://data.worldbank.org/indicator/SP.POP.TOTL?locations=QA (accessed 11.3.18).

World Bank, 2018c. Qatar GDP per capita, PPP (current international \$) [WWW Document]. URL https://data.worldbank.org/indicator/NY.GDP.PCAP.PP.CD?locations=QA\&year_high_desc=true (accessed 11.3.18).

World Bank, 2018d. Electric power consumption (kWh per capita) | Data [WWW Document]. URL https://data.worldbank.org/indicator/EG.USE.ELEC.KH.PC (accessed 3.16.18).

World Economic Forum, 2018. The Global Competitiveness Report.

World Health Organization, 2016a. Ambient air pollution: A global assessment of exposure and burden of disease. WHO.

World Health Organization, 2016b. Ambient (outdoor) air quality and health Guidelines. WHO.

World Resources Institute, 2017. Climate Watch: Data for Climate Action - GHG emissions [WWW Document]. URL https://www.climatewatchdata.org/ghg-emissions?breakBy=sector\&source=28\&version=1 (accessed 2.7.18).

Zareipour, H., Canizares, C.A., Bhattacharya, K., 2007. The Operation of Ontario's Competitive Electricity Market: Overview, Experiences, and Lessons. IEEE Trans. Power Syst. 22, 1782-1793. https://doi.org/10.1109/TPWRS.2007.907979 